\title{
Humanization of the mouse mammary gland by replacement of the luminal layer with genetically engineered preneoplastic human cells
}

Stephanie Verbeke ${ }^{1}$, Elodie Richard ${ }^{1}$, Elodie Monceau ${ }^{1}$, Xenia Schmidt ${ }^{1,2}$, Benoit Rousseau ${ }^{3}$, Valerie Velasco ${ }^{1,4}$, David Bernard ${ }^{5}$, Herve Bonnefoi ${ }^{1}$, Gaetan MacGrogan ${ }^{1,4}$ and Richard D Iggo ${ }^{1,2^{*}}$

\begin{abstract}
Introduction: The cell of origin for estrogen receptor a-positive (ERa+) breast cancer is probably a luminal stem cell in the terminal duct lobular units. To model these cells, we have used the murine myoepithelial layer in the mouse mammary ducts as a scaffold upon which to build a human luminal layer. To prevent squamous metaplasia, a common artifact in genetically-engineered breast cancer models, we sought to limit activation of the epidermal growth factor receptor (EGFR) during in vitro cell culture before grafting the cells.

Methods: Human reduction mammoplasty cells were grown in vitro in WIT medium. Epidermal growth factor in the medium was replaced with amphiregulin and neuregulin to decrease activation of EGFR and increase activation of EGFR homologs 3 and 4 (ERBB3 and ERBB4). Lentiviral vectors were used to express oncogenic transgenes and fluorescent proteins. Human mammary epithelial cells were mixed with irradiated mouse fibroblasts and Matrigel, then injected through the nipple into the mammary ducts of immunodeficient mice. Engrafted cells were visualized by stereomicroscopy for fluorescent proteins and characterized by histology and immunohistochemistry.

Results: Growth of normal mammary epithelial cells in conditions favoring ERBB3/4 signaling prevented squamous metaplasia in vitro. Normal human cells were quickly lost after intraductal injection, but cells infected with lentiviruses expressing CCND1, MYC, TERT, BMI1 and a short-hairpin RNA targeting TP53 were able to engraft and progressively replace the luminal layer in the mouse mammary ducts, resulting in the formation of an extensive network of humanized ducts. Despite expressing multiple oncogenes, the human cells formed a morphologically normal luminal layer. Expression of a single additional oncogene, PIK3CA-H1047R, converted the cells into invasive cancer cells. The resulting tumors were ERa+, Ki67+ luminal B adenocarcinomas that were resistant to treatment with fulvestrant.

Conclusions: Injection of preneoplastic human mammary epithelial cells into the mammary ducts of immunodeficient mice leads to replacement of the murine luminal layer with morphologically normal human cells. Genetic manipulation of the injected cells makes it possible to study defined steps in the transformation of human mammary epithelial cells in a more physiological environment than has hitherto been possible.
\end{abstract}

\footnotetext{
* Correspondence: r.iggo@bordeaux.unicancer.fr

${ }^{1}$ INSERM U916, Bergonié Cancer Institute, University of Bordeaux, 229 cours

de l'Argonne, Bordeaux 33076, France

${ }^{2}$ School of Medicine, University of St Andrews, Medical and Biological

Sciences Building, North Haugh, St Andrews KY16 9TF, UK

Full list of author information is available at the end of the article
} 


\section{Introduction}

Pioneering studies by the Weinberg group have shown that normal human cells can be fully converted into tumor cells by targeting a small number of processes known to be abnormal in cancer, including telomere maintenance, the restriction point, cell cycle checkpoints and apoptosis [1]. Human mammary epithelial cells transformed in this way have been widely used, but they frequently form tumors with histological features rarely seen in human breast cancer, in particular squamous cell carcinoma [2]. This is probably caused by excessive activation of the epidermal growth factor receptor (EGFR) [3]. Because squamous metaplasia increases with time in culture, current approaches attempt to shorten the transformation process as much as possible, often to as little as 24 hours $[4,5]$. Squamous cell changes are also commonly seen in transgenic mouse models of breast cancer, where part of the explanation may lie in mistargeting of oncogenes to myoepithelial or bipotent progenitor/stem cells rather than luminal stem cells [6].

About $70 \%$ of human breast cancers express the estrogen receptor $\alpha(E R \alpha, E S R 1)$, but genetically defined tumors based on transformation of normal human cells are usually ER $\alpha$-negative (ER-). Because the ESR1 gene is rarely amplified in breast cancer, ER $\alpha$ expression is normally ascribed to a lineage choice that traps the cells in an ER $\alpha+$ state. The most likely cell of origin for this event is a luminal progenitor or stem cell located in the terminal duct lobular unit (TDLU) [7].

Traditional breast cancer models based on injection of tumor cells directly into the mammary fat pad [8] or under the renal capsule [9] do not take into account the unique features of the microenvironment in which breast cancers develop. Behbod and colleagues recently described an intraductal injection technique that disseminates tumor cells throughout the mouse mammary ductal tree, including the TDLUs [10]. This approach places potential tumor cells at or near the normal point of origin of breast cancer and faithfully reproduces the histology of human ductal carcinoma in situ (DCIS) [11].

In this article, we describe an approach based on the Behbod intraductal injection technique using genetically engineered cells cultured in conditions favoring EGFR homolog 3 (ERBB3) signaling. Cells transduced with vectors expressing CCND1, MYC, TERT, BMI1 and a short-hairpin RNA targeting p53 (TP53) were able to form a morphologically normal luminal layer. Introduction of a single additional activated oncogene, PIK3CA-H1047R, converted them into $E R \alpha+$ invasive ductal adenocarcinomas.

\section{Methods}

\section{Lentiviral vectors}

The lentiviral plasmid vector expressing TERT and puromycin acetyltransferase (pac) (pSD-83) was described by
Duss et al. [12]. The vector expressing BMI1 and cyan fluorescent protein (CFP) (pER7) was constructed from pSD-84 [12] by replacing the pac gene with CFP by standard cloning. The vector expressing $M Y C$ and hygromycin phosphohydrolase (hph) (pSV32) was constructed by shuffling the $M Y C$ open reading frame from pSD-94 [12] into pLenti PGK Hygro DEST (Addgene plasmid 19066; Addgene, Cambridge, MA, USA) by Gateway cloning. The vector expressing CCND1 and neomycin phosphotransferase (npt) (pSV31) was constructed by Gateway cloning of the CCND1 open reading frame from pENTR-CCND1 (PlasmID HsCD00001252) into pLenti PGK Neo DEST (Addgene plasmid 19067). The pLVTH-sip53 vector expressing green fluorescent protein $(G F P)$ and a short-hairpin RNA targeting TP53 was obtained from Addgene (plasmid 12239). The vector expressing PIK3CA-H1047R and hph (pER157) was constructed by cloning the PIK3CA-H1047R open reading frame from pBABE-PIK3CA (PlasmID clone 25920) into pENTR1A to give pER152, then transferred by Gateway cloning into pLenti CMV/TO Hygro DEST (Addgene plasmid 17484). The vector expressing tdTomato (pER5) was kindly provided by Francois Moreau-Gaudry.

\section{Western blot analysis}

Cells were collected 4 to 7 days posttransfection and lysed in SDS-PAGE sample buffer [13]. Cell lysates were separated by SDS-PAGE and transferred onto nitrocellulose membranes. The membranes were blocked with $5 \%$ fat-free milk powder in $150 \mathrm{mM} \mathrm{NaCl}, 50 \mathrm{mM}$ Tris- $\mathrm{HCl}$, $\mathrm{pH}$ 8.0, 0.1\% Tween 20 (TBST) and incubated overnight at $4^{\circ} \mathrm{C}$ with the following antibodies: telomerase catalytic subunit (TERT) (Y182), phosphatidylinositol 3-kinase (PI3K) p110 $\alpha$ (04-399), $\Delta \mathrm{N}-\mathrm{p} 63$ (p40 [5-17] PC373), GATA binding protein 3 transcription factor (GATA3) (09-076) (EMD Millipore, Billerica, MA, USA); B lymphoma Moloney murine leukemia virus insertion region 1 (BMI1) (D20B7), keratin 18 (DC10), cyclin D1 (DCS6), myc (D84C12), Akt (9272), phospho-Akt-T308 (4056/ 244 F9), ERBB3 (4754) (Cell Signaling Technology, Danvers, MA, USA); Forkhead box A1 transcription factor (FOXA1) (Ab55-178; Abcam, Cambridge, UK); AGR2 (1C3), tubulin (B-5-1-2) (Sigma-Aldrich, St Louis, MO, USA); keratin 14 (LL002, gift from Birgit Lane); ER $\alpha$ (Ab-16, RB-1493) (Thermo Scientific, Waltham, MA, USA) and p53 (D01, gift from David Lane). After three washes in TBST, bound primary antibodies were detected by incubation with horseradish peroxidase (HRP)-conjugated anti-rabbit, anti-mouse or anti-goat immunoglobulin G (IgG) (GE Healthcare Life Sciences, Pittsburgh, PA, USA) at room temperature for 1 hour, washed again in TBST and visualized using enhanced chemiluminescence reagents (GE Healthcare Life Sciences). Images were captured with a Fusion FX7 
scanner (Vilber Lourmat, Marne-la-Vallée, France) or Hyperfilm ECL (GE Healthcare Life Sciences).

\section{Flow cytometry analysis}

Cells were grown in WIT medium (mammary culture medium developed by Tan Ince [2]), detached using $0.5 \%$ trypsin-ethylenediaminetetraacetic acid (Invitrogen, Carlsbad, CA, USA), pelleted, washed and counted. A total of $10^{5}$ cells were incubated for 20 minutes with the following antibodies: allophycocyanin (APC)-conjugated anti-epithelial cell adhesion molecule (EPCAM), phycoerythrin (PE)-conjugated anti-CD49f and PE-conjugated anti-CD10 (BD Biosciences, San Jose, CA, USA). Nonspecific PE-IgG2a and APC-IgG1 (BD Biosciences) were used as control antibodies. The gates marking the quadrants in the figures were set to exclude cells labeled by the control antibodies. Cells were washed three times, then analyzed on a FACSCalibur flow cytometer (BD Biosciences) using CellQuest Pro software.

\section{Immunofluorescence and immunohistochemistry}

Paraffin-embedded mammary tissues were sectioned at $4 \mu \mathrm{m}$, deparaffinized and boiled in $\mathrm{pH} 6.0$ citrate buffer to retrieve antigens. For immunofluorescence, sections were blocked in Dako REAL Peroxidase-Blocking Solution S2023 for 10 minutes and incubated with primary antibodies specific for p63 (4A4, 1:40 dilution; Dako, Carpinteria, CA, USA) and GFP (ab290, 1:800 dilution; Abcam) for 30 minutes. Donkey anti-rabbit IgG conjugated to Alexa Fluor 488 (1:400 dilution; Invitrogen) was used to detect the anti-GFP antibody. An M.O.M. ImmPRESS HRP (Peroxidase) Polymer Kit (MP-2400; Vector Laboratories, Burlingame, CA, USA) and cyanine 3-conjugated goat anti-HRP (123-165-021, 1:200 dilution; Jackson ImmunoResearch Laboratories, West Grove, PA, USA) were used according to the manufacturers' instructions to detect the anti-p63 antibody. Sections omitting the primary antibody were used as negative controls. Nuclei were visualized with 4',6diamidino-2-phenylindole, and sections were mounted with Fluoromount mounting medium (Sigma-Aldrich). Slides were scanned on a Leica spinning disk DM6000 B confocal microscope (Leica Microsystems, Wetzlar, Germany). Immunohistochemical staining was performed on a BenchMark ULTRA instrument (Ventana Medical Systems, Tucson, AZ, USA) according to the manufacturer's protocol with the following antibodies: ER $\alpha$ (SP1, 32 minutes, prediluted; Ventana Medical Systems), progesterone receptor (1E2, 12 minutes, prediluted; Ventana Medical Systems), p53 (DO7, 32 minutes, 1:50 dilution; Dako), keratin 5/6 (D5/16B4, 32 minutes, 1:50 dilution; Dako), keratin 14 (LL002, 40 minutes + amplification, prediluted; Ventana Medical Systems), keratin 8/18 (5D3, 20 minutes, 1:200 dilution; Novocastra/Leica Microsystems,
Milton Keynes, UK), keratin 19 (A53-b/A2.26, 32 minutes, prediluted; Ventana Medical Systems), keratin 7 (SP52, 32 minutes, prediluted; Ventana Medical Systems), smooth muscle actin (SMA) (1A4, 32 minutes, 1:12,000 dilution; Sigma-Aldrich), p63 (4A4, 32 minutes, 1:100 dilution; Dako), Ki67 (30-9, 32 minutes, prediluted; Ventana Medical Systems) and GFP (number sc-9996, B-2, 32 minutes, 1:400 dilution; Santa Cruz Biotechnology, Santa Cruz, CA, USA).

\section{Bioinformatics}

To identify the normal cell types expressing EGFR family members in human reduction mammoplasty tissue, the most variable probes for each EGFR family member were selected from the Lim et al. Gene Expression Omnibus [GEO:GSE16997] series matrix file [14]. The error bars in Figure 2A are standard errors of the mean. The $P$-values shown are derived from $t$-tests performed to compare the mature luminal with the indicated populations. The tumor analysis in Figure $2 \mathrm{~B}$ and $2 \mathrm{C}$ was performed on [GEO:GSE6861] Affymetrix GeneChip Human X3P Array (Affymetrix, Santa Clara, CA, USA) gene expression data derived from large operable or locally advanced breast cancer $[15,16]$. The .CEL files were normalized with robust multiarray average (RMA) in $R$ [17], filtered to remove probe sets spanning a region $<56$ base pairs, and the most variable probe sets for EGFR family members were selected based on the standard deviation across all the tumors. The classification shown in Figure $2 \mathrm{~B}$ and $2 \mathrm{C}$ into luminal, molecular apocrine and basal-like tumors is based on expression of FOXA1 (positive in luminal and molecular apocrine tumors) and ESR1 (positive in luminal tumors). Both genes show strongly bimodal expression; the cutoff is the nadir between the two peaks of the bimodal distributions. This classification splits breast tumors into the three groups described by Farmer et al. [18]. FOXA1 was used instead of $A R$ because the X3P probes work slightly better (both genes are excellent markers for luminal and molecular apocrine tumors). The plot in Figure 2B shows the raw expression values generated by RMA. These values were converted to a distribution with the density command in $\mathrm{R}$ using the default parameters, then the maximum of each distribution was scaled to 1 to make it easier to compare the distributions in Figure 2C.

\section{Cell biology}

Reduction mammoplasty samples were donated by healthy premenopausal women between the ages of 21 and 40 with no previous history of breast cancer. The study was approved by the Tayside Tissue Bank Ethics Committee (project TR000015), and patients gave us their written informed consent to participate. Breast primary epithelial cells (BPECs) were prepared by using 


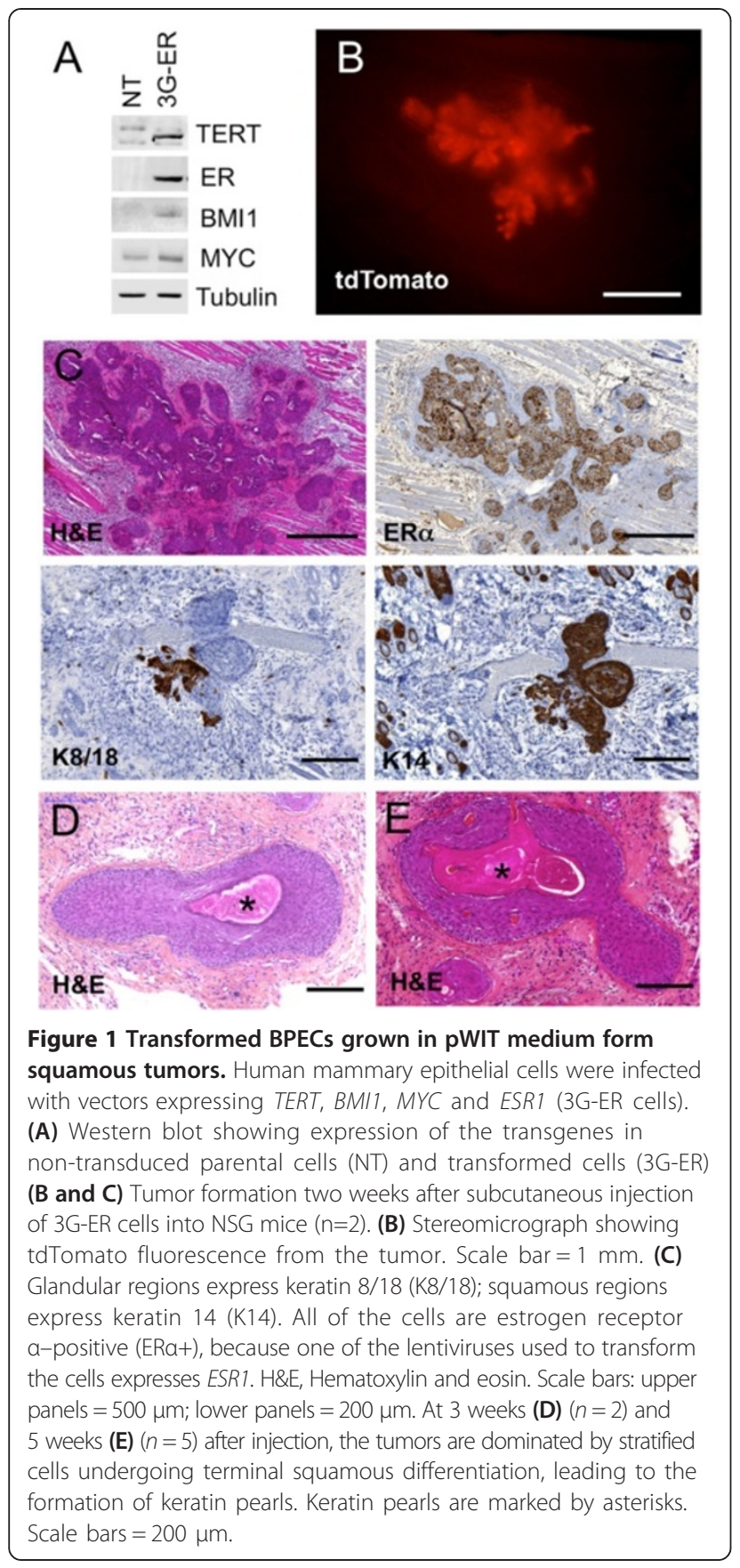

standard techniques [19] and cultured in a $37^{\circ} \mathrm{C}, 5 \% \mathrm{CO}_{2}$, $5 \% \mathrm{O}_{2}$ incubator in Primaria dishes (BD Biosciences) in WIT medium containing $10 \mathrm{ng} / \mathrm{ml}$ basic fibroblast growth factor and either $10 \mathrm{ng} / \mathrm{ml}$ epidermal growth factor (EGF) for pWIT or $5 \mathrm{ng} / \mathrm{ml} \mathrm{NRG1} \mathrm{and} 10 \mathrm{ng} / \mathrm{ml}$ AREG for svWIT [2]. Low-passage cultures of BPECs were sequentially infected with lentiviruses and selected for 4 to 10 days in media supplemented with $2 \mu \mathrm{g} / \mathrm{ml}$ puromycin, $50 \mu \mathrm{g} / \mathrm{ml}$ hygromycin B or $500 \mu \mathrm{g} / \mathrm{ml} \mathrm{G} 418$, as appropriate. Viral particles were produced by calcium phosphate transfection of $293 \mathrm{~T}$ cells [20]. Infections were performed at a multiplicity of 10 infectious units per cell based on the MCF7 titer. The final 4G-shp53PI3K cells were uniformly positive for CFP and GFP, which are carried by the BMI1 and shp53 vectors, respectively, but showed heterogeneous staining for tdTomato because the tdTomato vector was added last, not selected with an antibiotic and conferred no growth advantage on the cells. For proliferation assays, cells were treated with 2 $\mathrm{nM} 17 \beta$-estradiol or $1 \mu \mathrm{M}$ fulvestrant and counted at each time point with a Coulter counter (Beckman Coulter, Brea, CA, USA). To test for significant differences between the growth curves in Figure $4 \mathrm{~B}$ and Figure $10 \mathrm{C}$, the slopes were compared after linear regression on logged data with the $\operatorname{lm}$ (linear model) function in $\mathrm{R}$, with a correction in Figure $4 \mathrm{~B}$ for performing three tests.

\section{Xenografts}

The study was performed in accordance with European Community Standards of Care and Use of Laboratory Animals under level 2 containment at the University of Bordeaux. Approval was granted for the animal experiments by the Comite d'Ethique pour l'Experimentation Animal (CEEA50) Ethics Committee, Bordeaux (project number 5012034-A). For xenografts, 100,000 BPECs and

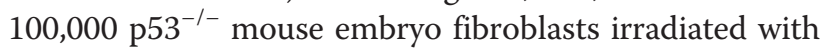
30 Gy were mixed with $10 \%$ growth factor-reduced Matrigel (BD Biosciences) and injected into 6-week-old female NSG mice (nonobese diabetic, severe combined immunodeficiency, interleukin 2 receptor gamma chainnull, strain number 005557; The Jackson Laboratory, Bar Harbor, ME, USA). The injection volumes were $100 \mu \mathrm{l}$ for subcutaneous injections and $10 \mu \mathrm{l}$ for intraductal injections [10]. Tumor size after subcutaneous injection was measured with a PhotonIMAGER (Biospace, Paris, France) and scaled to the size at the first time point in each tumor group. To identify significant differences, $t$ tests were performed in $\mathrm{R}$ on logged data with a correction for performing five tests in Figure 6A and ten tests in Additional file 2: Figure S2E and S2F. To measure tumor size after intraductal injection, the glands were removed at the end of the experiment and scanned as a single group with the PhotonIMAGER.

\section{Results}

A new genetically defined human adenocarcinoma model WIT medium was developed to prevent squamous metaplasia of genetically defined mammary tumors [2]. When we grew reduction mammoplasty cells in WIT medium, transformed them with TERT, BMI1, ESR1 and MYC, and injected them subcutaneously into immunodeficient mice, they formed mixed tumors that rapidly became entirely squamous with the appearance of stratification and keratin pearls. Figure $1 \mathrm{~B}$ to $1 \mathrm{E}$ show the morphology of the tumors. EGFR family members show 

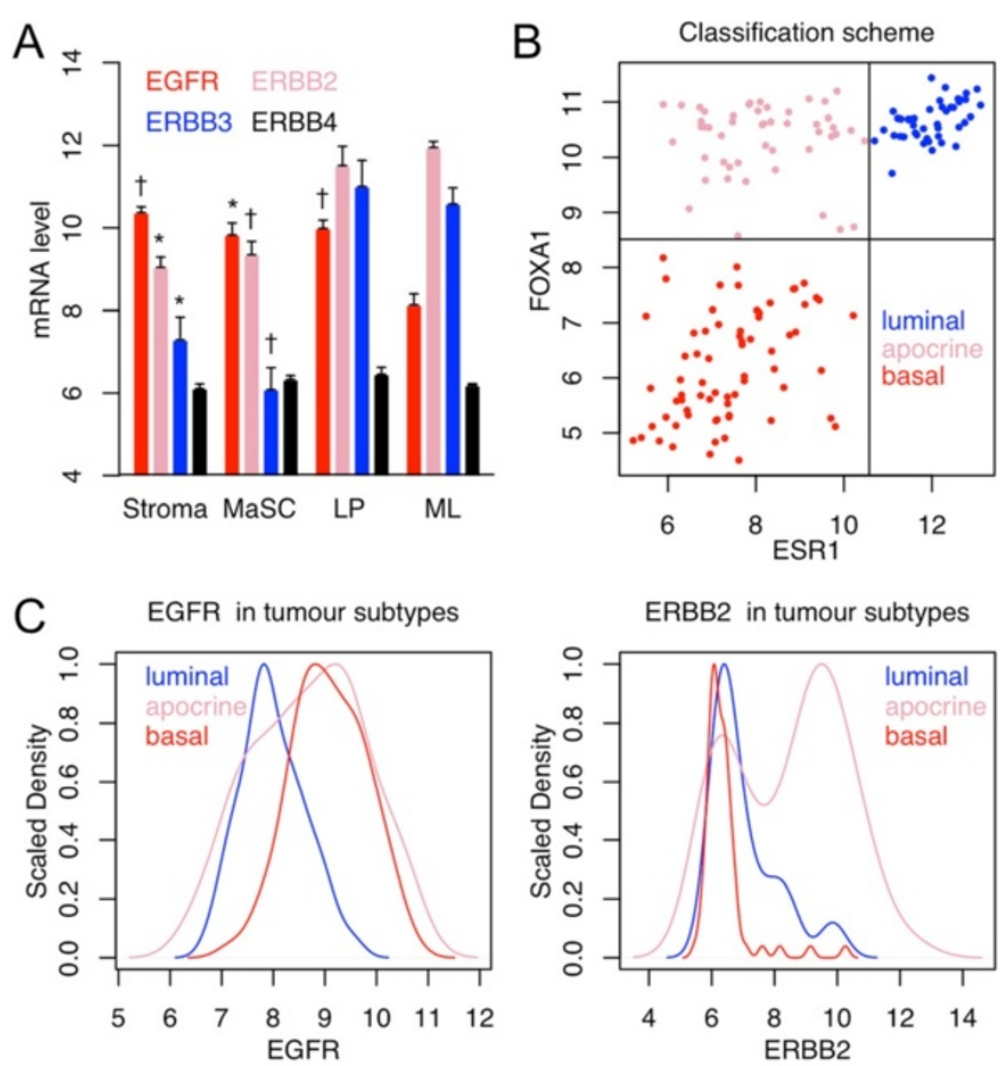

ERBB2 in tumour subtypes

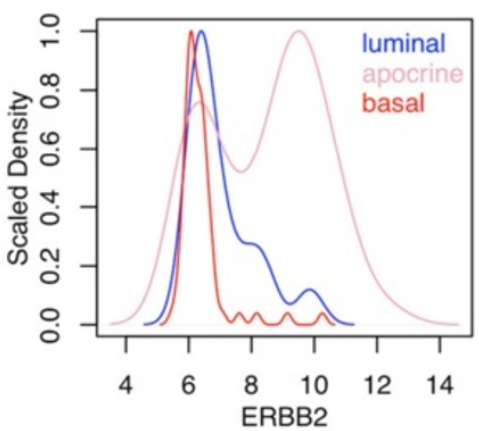

ERBB3 in tumour subtypes

ERBB4 in tumour subtypes
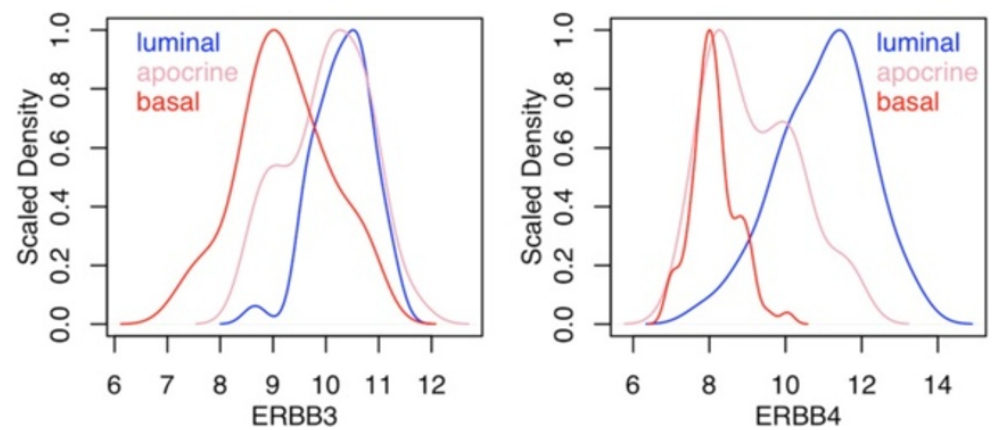

Figure 2 Epidermal growth factor receptor family gene expression in normal and tumor cells. (A) Illumina gene expression data from normal human reduction mammoplasty cells LP, Luminal progenitor; MaSC, Mammary stem cell; ML, Mature luminal. Error bars represent standard error of the mean. $n=3 ;+P<0.01 ;{ }^{*} P<0.05$; the $P$-values are for comparisons of $M L$ with the other groups. (B and $\mathbf{C}$ ) Affymetrix gene expression data for large operable or locally advanced breast cancer. The scatterplot in (B) shows how the tumors were classified into luminal (ER+FOXA1+, 43 samples), molecular apocrine (ER-/FOXA1+, 49 samples) and basal-like (ER-/FOXA1-, 69 samples). The plots in (C) show the expression profiles of EGFR family members in each tumor class. The distributions are strikingly bimodal (see text for details). The maximum density for each distribution is scaled to 1 to facilitate comparison of the different tumor classes.

differences in expression in normal mammary epithelial cell subsets: EGFR expression is significantly lower in mature luminal cells than in other subsets; $E R B B 3$ expression is significantly lower in stem cells than in mature luminal cells; and luminal progenitors have an intermediate phenotype (Figure 2A) [14,21]. EGFR family members show strikingly bimodal patterns of expression in human breast tumors: $E G F R$ is higher in basal-like and molecular apocrine tumors; $E R B B 2$ is higher in molecular apocrine tumors; $E R B B 3$ is higher in luminal and molecular apocrine tumors; and $E R B B 4$ is higher in luminal tumors (Figure 2B, and 2C) $[15,16,18]$. On the basis of these observations, histopathological data showing EGFR expression by myoepithelial cells, keratinocytes and 


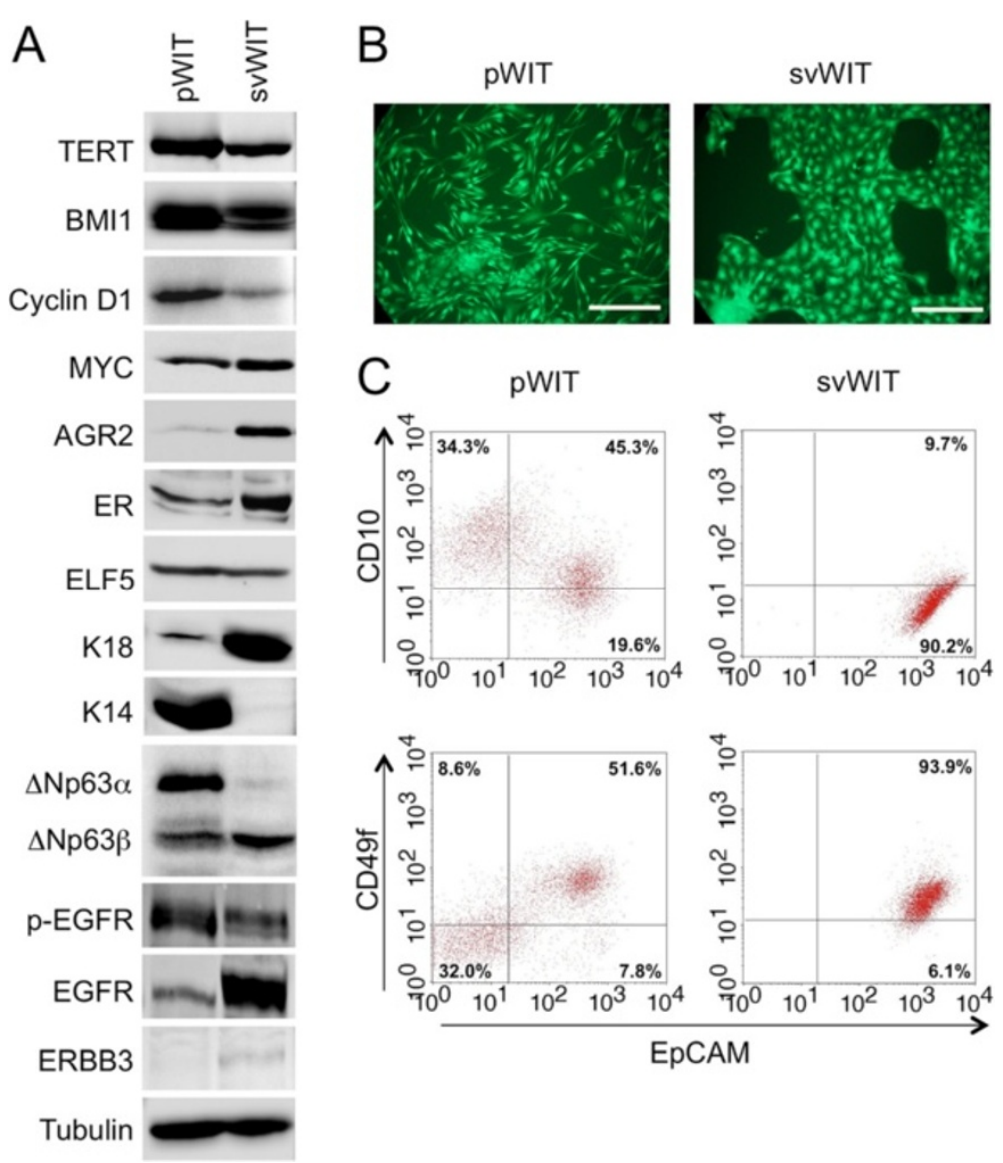

Figure 3 Comparison of WIT medium containing EGF to WIT medium containing amphiregulin and neuregulin. Human mammary epithelial cells were infected with vectors expressing TERT, BMI1, CCND1 and MYC. (A) Western blots showing that the transgenes are expressed. The cells in medium containing amphiregulin and neuregulin (sVWIT) have luminal characteristics. The cells in medium containing EGF (pWIT) have stronger phosphorylation of EGFR. (B) Photomicrographs showing that cells in pWIT are a mixture of spindle shaped and rounder cells, whereas cells in svWIT have a more uniform cobblestone appearance. Scale bars $250 \mu \mathrm{m}$. (C) Flow cytometry shows that cells in svWIT have a putative luminal progenitor phenotype (CD49+/EPCAM+) whereas cells in pWIT are a mixture of putative luminal progenitors and myoepithelial cells. The quadrants were defined by the isotype controls.

squamous tumors $[22,23]$ and the fact that EGF promotes expansion of the myoepithelial layer in shortterm organoid cultures [3], we reasoned that it might be possible to reduce squamous metaplasia in engineered tumor models by decreasing the activation of EGFR and increasing that of ERBB3 and ERBB4. To test this hypothesis, we grew normal reduction mammoplasty cells in WIT medium containing either EGF (pWIT medium) or amphiregulin (AREG) plus neuregulin (NRG1) (svWIT medium). Parallel cultures in the two media were infected first with TERT and BMI1 viruses and then superinfected with $C C N D 1$ and $M Y C$ viruses to produce 4G cells. Expression of the transgenes was confirmed by Western blotting (Figure 3A and Additional file 1: Figure S1A). Cells grown in pWIT formed loose colonies of spindle-shaped cells mixed with larger cells, whereas cells in svWIT formed tighter colonies of round cells that were more uniform in appearance (Figure 3B). Flow cytometry showed that the svWIT culture was homogeneous, with a single population high in EPCAM expression, low in CD10 expression and intermediate in CD49f expression (Figure 3C). The cells in pWIT contained two populations, one CD49f-/CD10+/EPCAMand the other CD49f+/CD10-/EPCAM+. The CD10+ population in pWIT could correspond to myoepithelial cells. The EPCAM+ cells in both media are presumably luminal cells. The EPCAM level is higher in svWIT than pWIT, suggesting that the cells are more differentiated in svWIT. Western blotting showed that the switch from EGF to amphiregulin and neuregulin in svWIT decreased the level of EGFR receptor tail phosphorylation, despite an increase in the amount of the protein (Figure 3A), consistent with weaker activation of EGFR and decreased receptor turnover. Western blotting of the cells in pWIT showed that they express keratin 14 and $\Delta \mathrm{N}$-p63 $\alpha$ strongly, confirming the suggestion arising 

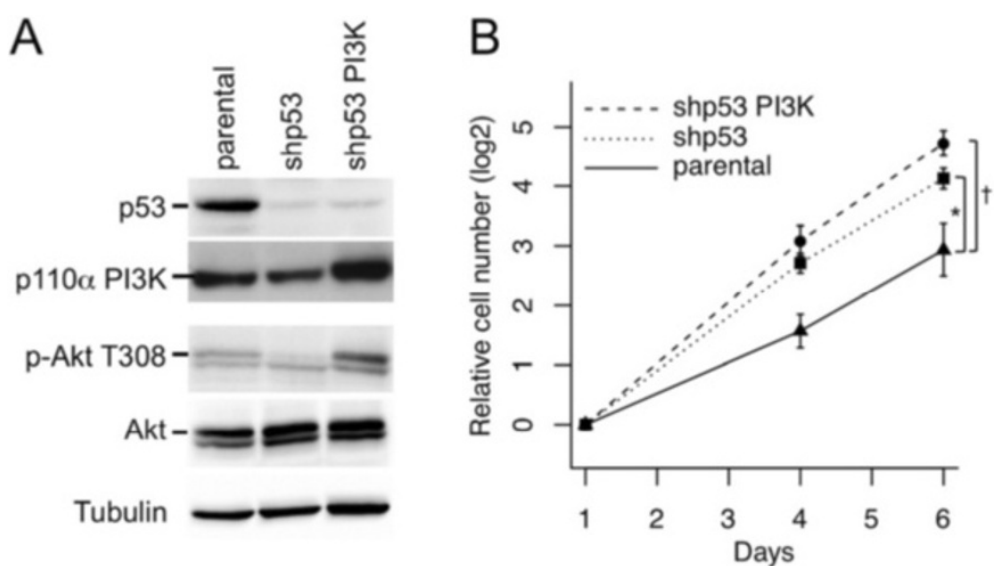

Figure 4 Silencing of p53 and activation of phosphatidylinositol 3-kinase in $\mathbf{4 G}$ cells. (A) Western blots showing that the shp53 vector silences p53 expression and the PIK3CA vector increases phosphatidylinositol 3-kinase (PI3K) expression and Akt phosphorylation on T308.

(B) Growth curves comparing parental 4G cells with cells infected with the shp53 and PIK3CA vectors. Error bars represent standard error of the mean. $+P<0.001 ;{ }^{*} P<0.05 ; n=5$ biological replicates.

from the flow cytometry data that at least one of the populations in pWIT is myoepithelial or squamous. The cells in svWIT expressed luminal markers (AGR2, ERBB3 and keratin 18) (Figure 3A), as well as ER $\alpha$ and ELF5 (Figure 3A), but not FOXA1 or GATA3 (Additional file 1: Figure S1B). ER, FOXA1 and GATA3 are markers for mature hormone-sensing cells, whereas
ELF5 is a marker for the secretory lineage [24]. Coexpression of ER and ELF5, as seen in the cells grown in svWIT medium, has been proposed to mark luminal progenitors that have not yet committed to one lineage [24]. We conclude that a shift in the balance of EGFR family signaling in favor of ERBB3 selects for cells that share some features with luminal progenitors
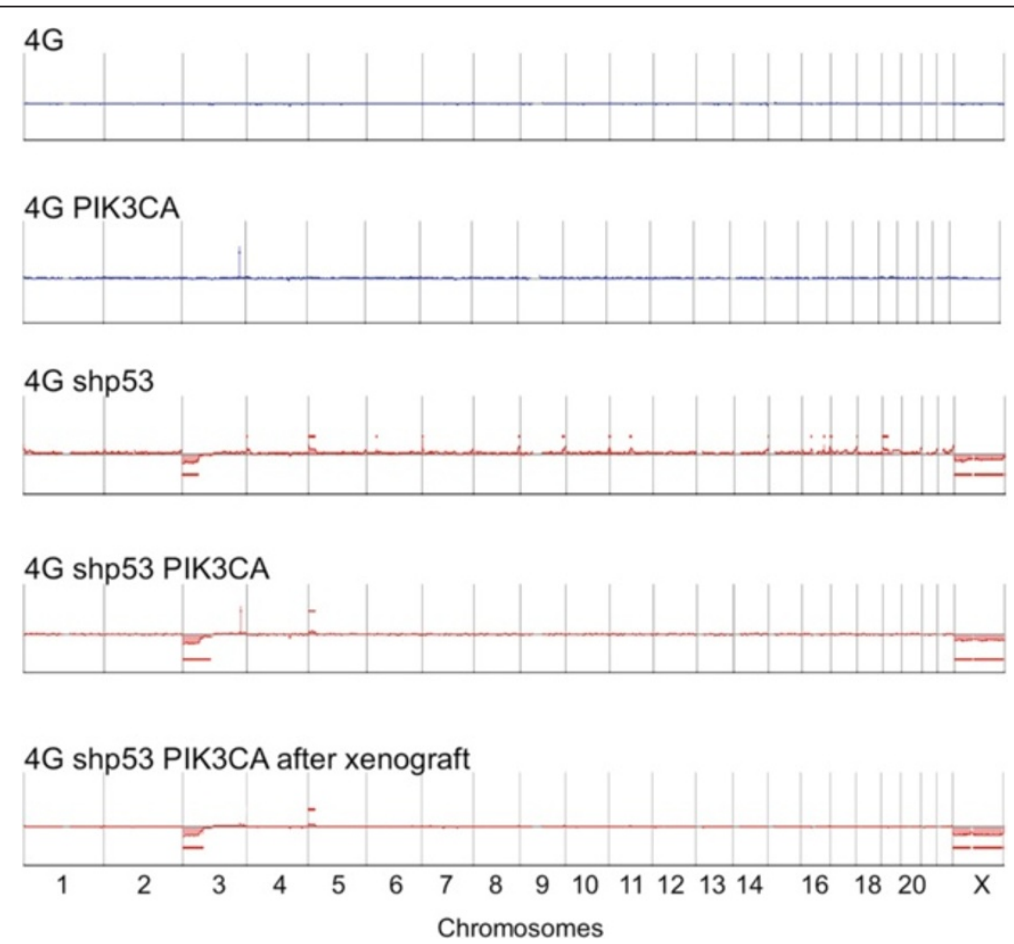

Figure 5 Genomic profiles at different stages in the transformation protocol. Comparative genomic hybridization plots of $4 \mathrm{G}$ cells and $4 \mathrm{G}$ cells infected with the PIK3CA vector show no copy number changes. Silencing of p53 in the 4G cells leads to loss of chromosome $\mathrm{X}$ and minor changes on chromosomes 3 and 5 which do not progress after introduction of the PIK3CA vector. The spike on chromosome 3q in 4G-PIK3CA and 4G-shp53-PIK3CA cells is caused by four exonic probes in the PIK3CA locus. There were no additional changes after passage in mice. 
and prevents overgrowth by myoepithelial and squamous cells.

\section{Tumor formation by cells grown in svWIT medium}

It was not possible to compare the phenotype of tumors formed by $4 \mathrm{G}$ cells grown in the two media, because the cells are not tumorigenic. To transform them fully, they were infected with lentiviruses expressing PIK3CAH1047R and a short-hairpin RNA targeting TP53 (shp53). Western blotting showed that the shp53 vector reduced the amount of p53 (Figure 4A). Cells infected with the PIK3CA vector showed increased expression of PI3K and increased phosphorylation of AKT on T308, indicating that PDK1 was activated by PI3K (Figure 4A). Growth curves showed that the shp53 and PIK3CA vectors significantly increased the growth rate (Figure $4 \mathrm{~B}$ ). As expected for genetically defined models of this type, comparative genomic hybridization (CGH) profiles were completely flat until p53 was silenced, but even cells containing all six vectors had only minor changes (loss of 3p21, gain of 5p14, loss of X) (Figure 5). Interestingly, the breakpoint on 3p21 truncates PBRM1 (BAF180), a known breast cancer tumor suppressor gene [25]. To determine whether the cells were tumorigenic in vivo, they were injected subcutaneously into immunodeficient mice. Only the cells transduced with both the shp53 and the PIK3CA vectors could form progressively growing tumors (Figure 6A; the images of mice show how the data were collected, and the graph shows fluorescence normalized to the value one week after injection). Histological examination showed that the tumors were grade 3 adenocarcinomas (Figure 6B). The tumor cells stained strongly with anti-GFP antibody and with humanspecific antibodies against keratins 7 and 19, confirming that they were carcinoma cells [26] derived from the injected human epithelial cells. Cells in contact with the mouse stroma expressed p63 and keratin 14, suggesting that they might be trying to form a myoepithelial boundary layer (Figure 6B; the stroma is marked by an asterisk). Cells in the main tumor mass expressed keratins $5 / 6$ and $8 / 18$. The overall pattern of keratin staining indicates that the tumors were adenocarcinomas rather than squamous carcinomas, but the presence of scattered p63-positive cells and the induction of myoepithelial genes at boundaries with mouse stroma suggest that the cells may retain some common progenitor features. Importantly, the tumor cells were positive for ER $\alpha$ and Ki67 but negative for PGR (Figure 6B). The experiment was repeated with two other mammoplasties (XS03 and XS05), and expression of TERT, BMI1, MYC and CCND1 and activation of PI3K were confirmed by Western blotting (Additional file 2: Figures S2A and S2B). Flow cytometry showed the presence of a single EPCAM+ luminal population (Additional file 2: Figures S2C and S2D).
Subcutaneous xenografts only formed tumors following introduction of the PIK3CA-H1047R vector (Additional file 2: Figures S2E and S2F). We conclude that cells transformed in medium containing amphiregulin and neuregulin form luminal B mammary adenocarcinomas with squamous metaplasia of cells in contact with the mouse stroma.

\section{Orthotopic tumor formation}

Behbod and colleagues recently described a new approach to modeling DCIS by injecting cells through the nipple directly into the mouse mammary ductal tree [10]. To test whether exposure to this more physiological environment would correct the transformed phenotype of the 4G-shp53-PIK3CA cells, we mixed them with irradiated mouse fibroblasts and laminin-rich extracellular matrix (Matrigel) and injected the mixture into the ducts. Fibroblasts and Matrigel were used to promote the survival of the epithelial cells in the perioperative period, but we have not formally tested whether they increase the rate of engraftment. In contrast to the Kuperwasser approach [27], the fibroblasts were murine in origin and injected into the ducts, not into the stroma. Six-week-old mice were injected because the majority of the primary ductal tree is present, providing a large surface area for the human cells to colonize, but the ducts are still growing and forming side branches at this age, so the cells can potentially be incorporated into ducts as they are laid down.

Three weeks after injection, mice were killed and their mammary glands were harvested for examination by stereomicroscopy (Figure 7A). Clusters of fluorescent cells were scattered throughout the injected glands. At higher magnification, the main ducts and side branches are clearly visible (Figure $7 \mathrm{~B}$ ). The injected cells expressed red, blue and green fluorescent proteins, but the strength of the red signal was variable in different clones because the number of copies of the tdTomato provirus varied between cells. Clusters of yellow cells alternate with clusters of green cells in the right panel in Figure 7B, indicating that different ratios of red and green vector were present. We can infer that hundreds of cells successfully seeded independent tumor foci throughout the gland. The hematoxylin and eosin (H\&E) staining showed that the mammary ducts were filled with cells resembling the pattern seen in DCIS (Figure 7C). Immunohistochemistry (IHC) for GFP confirmed that the tumor cells were derived from the injected human cells. IHC for p63 and SMA showed that the myoepithelial layer was present at this stage (3 weeks after injection) (Figure 7C), indicating that the tumor was a DCIS, but there were fewer myoepithelial cells than in normal murine ducts (Figure 8). As expected, the myoepithelial cells did not stain for GFP, indicating that they were murine in origin (Figure 8: red 

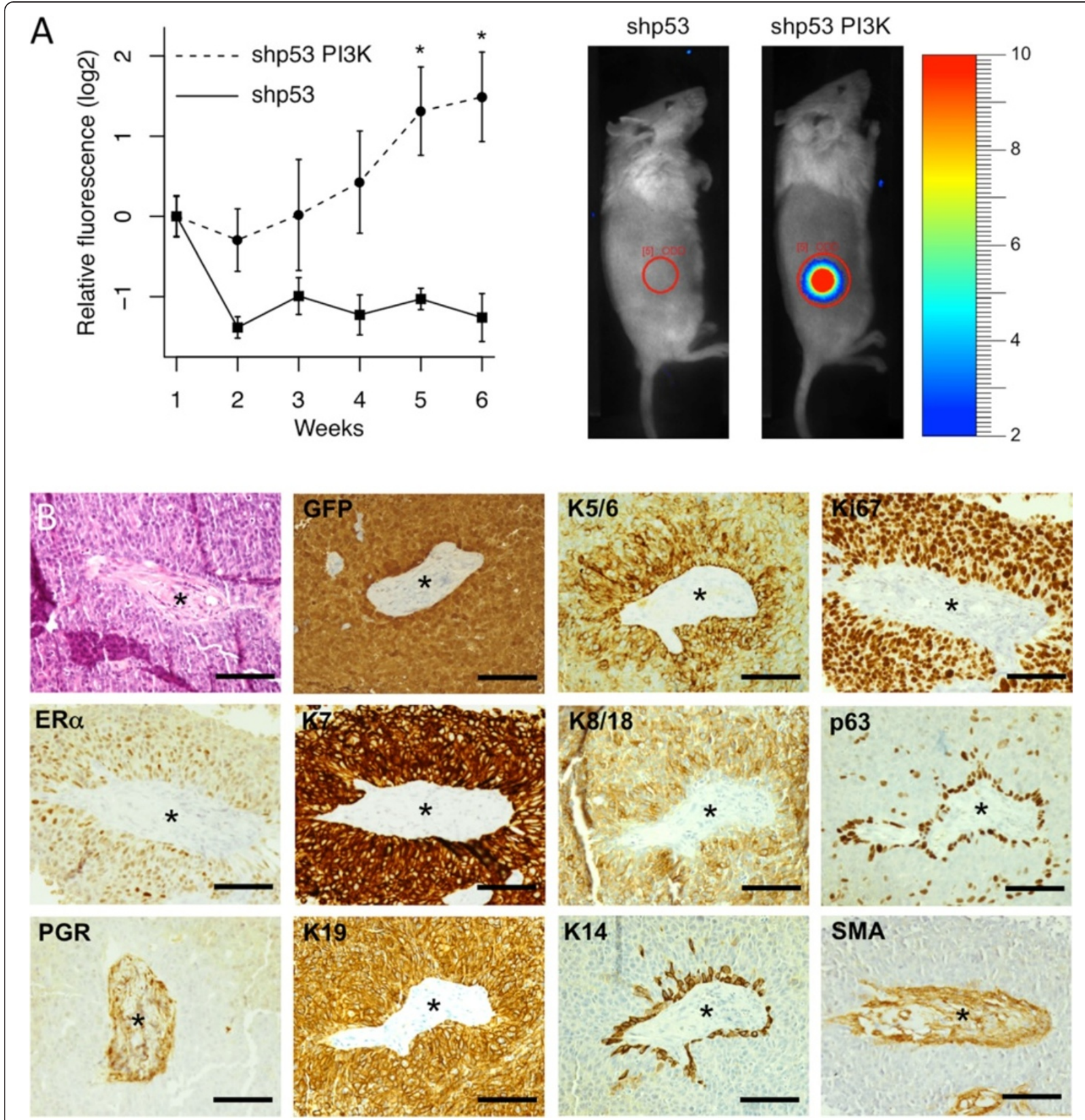

Figure 6 Subcutaneous tumor formation requires activation of phosphatidylinositol 3-kinase. (A) Red fluorescence was used to measure subcutaneous tumor growth. Fluorescence in the circled region ("ODD") in photons per second per square centimeter per steradian was normalized to the starting value one week after injection. $n=6$; ${ }^{*}, p<0.05$. (B) Histopathological (H\&E stain) and immunohistochemical analyses show that the tumor is an ERa+, Ki67+ adenocarcinoma. The asterisks mark an island of mouse stroma surrounded by human tumor cells. The antibody against the progesterone receptor (PGR) gives a non-specific cytoplasmic stain in the stroma. Scale bars $=100 \mu \mathrm{m}$.

arrow, normal duct; green arrow, DCIS). Intraductal injection of cells from the other mammoplasties also produced $\mathrm{ER} \alpha+\mathrm{DCIS}$ (Additional file 2: Figure S2G). The tumor cells were all positive for keratins 7, 8/18 and 19; most were weakly positive for keratins $5 / 6$; a few were positive for keratin 14. (Figure 7C). This mixed luminal/basal pattern has been reported to occur in one-fourth of primary operable breast tumors [28]. Interestingly, the cells were positive for ER $\alpha$ and Ki67 but negative for PGR (Figure 7C; the PGR stain is negative relative to control cells in the same section).

Six weeks after injection, stereomicroscopy showed dilated ducts packed with fluorescent cells. There was again variable red staining, indicating that multiple 

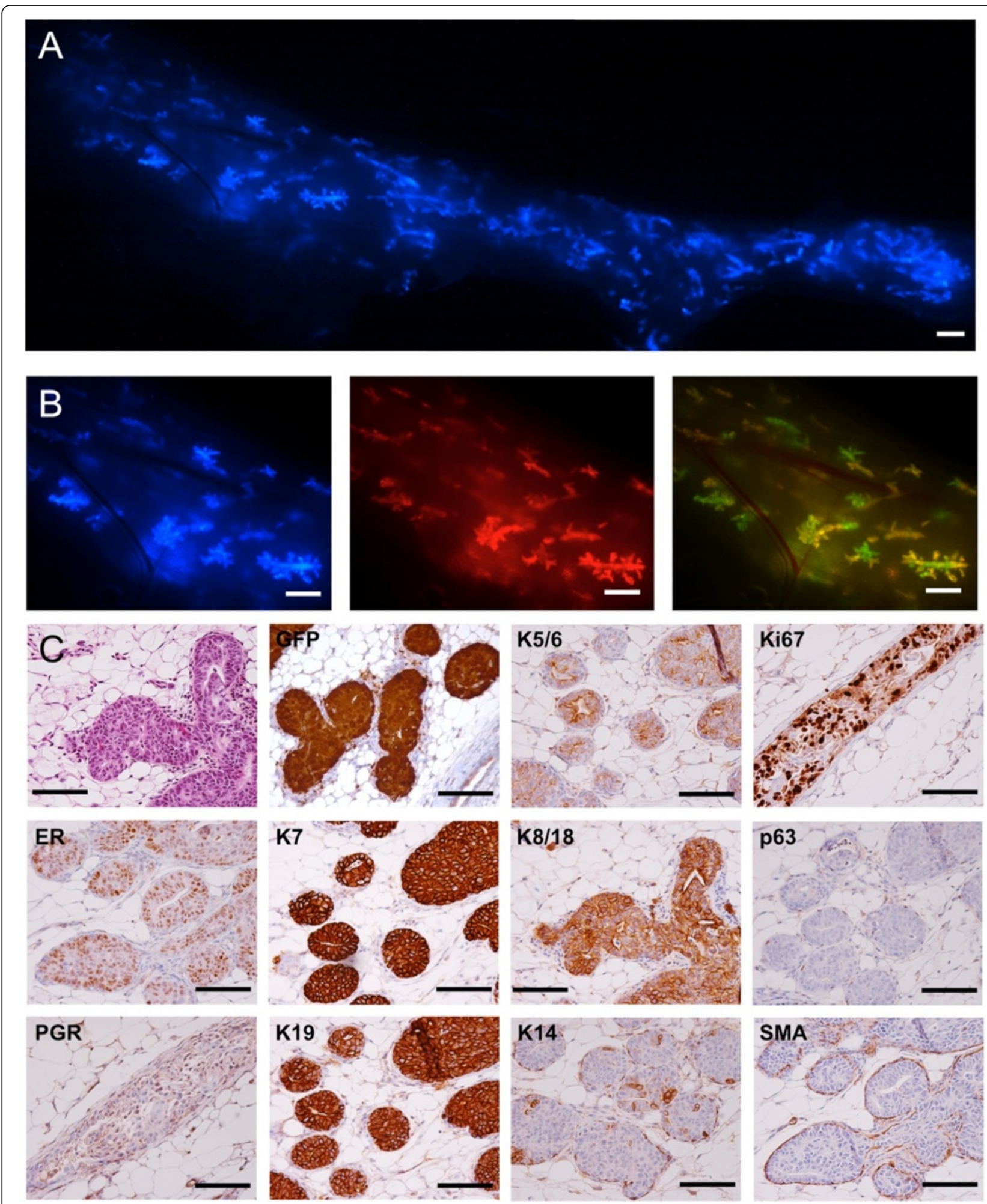

Figure 7 Ductal carcinoma in situ formation 3 weeks after intraductal injection of 4G-shp53-PI3K tumor cells. (A) Composite image showing human cells expressing cyan fluorescent protein scattered throughout the gland. (B) Enlarged images from $\mathbf{A}$. The right panel shows alternating clusters of yellow and green cells. (C) Hematoxylin and eosin and immunohistochemical stains showing estrogen receptor a-positive $(\mathrm{ERa}+)$ and Ki67+ ductal carcinoma in situ (DCIS). The progesterone receptor (PGR) staining is negative in the tumor cell nuclei relative to controls on the slide. GFP, Green fluorescent protein; K, Keratins; SMA, Smooth muscle actin. Scale bars $=1 \mathrm{~mm}$ (A and B) and $100 \mu \mathrm{m}$ (C). 

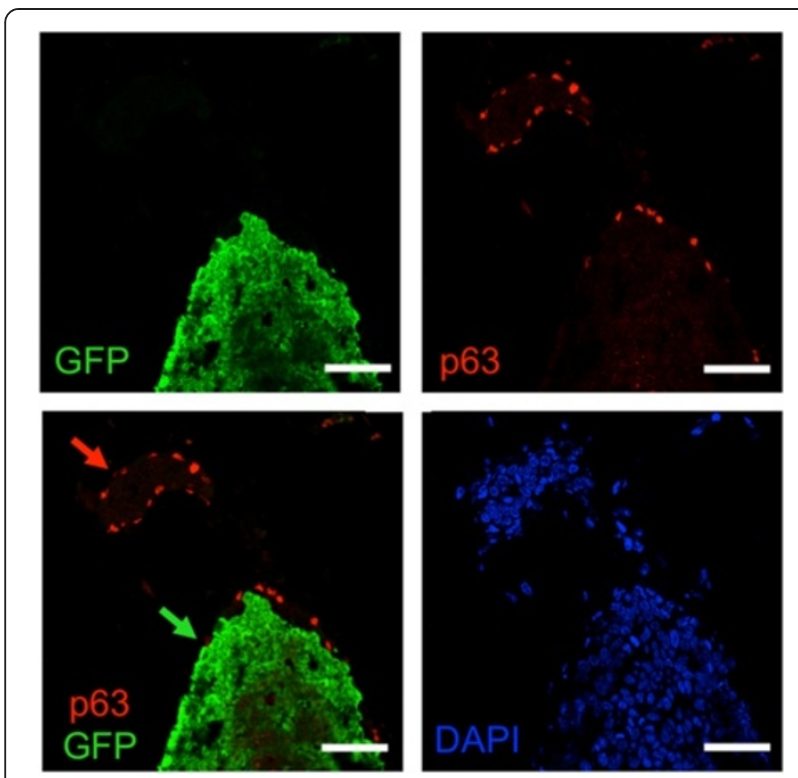

Figure $\mathbf{8}$ The myoepithelial layer is murine in humanized glands. Ducts humanized with 4G-shp53 cells were costained for p63 (red), GFP (green) and DNA (DAPI, blue) $(n=3)$. All injected human cells express GFP strongly. Green arrow, human luminal cells in a humanized duct; red arrow, murine myoepithelial cells in a murine duct. Scale bars $50 \mu \mathrm{m}$.

clones were present, but large regions showed homogeneous staining, suggesting that individual clones had expanded to fill those regions (Figure 9A). Eight weeks after injection, the tumor had spread to fill large contiguous parts of the ductal tree (Figure 9B). H\&E staining showed that the tumor had broken out of the ducts and started to invade the mammary fat (Figure 9C). Keratin 19 and GFP staining confirmed that the tumor cells were derived from the injected human cells. The tumor cells still expressed ER $\alpha$, but the intensity of keratin $8 / 18$ staining became weaker and that of keratin 14 stronger as the cells migrated from the ducts into the stroma. This was accompanied by histological features of early squamous differentiation (pink cytoplasmic staining, marked by arrows in Figure 9C, without stratification or keratin pearls). We conclude that loss of environmental cues when the tumor breaks free from the ducts allows the cells to evolve toward a more adenosquamous phenotype, although the squamous differentiation is much less pronounced than in our previous model [12].

Because the tumors are potentially a model for highgrade, ER $\alpha$-positive breast cancer, they were tested for estrogen dependence. Western blotting showed that in vitro treatment with fulvestrant reduced the level of $\mathrm{ER} \alpha$ (Figure 10A), but the growth rate was unaffected (Figure 10B and 10C). The cells were xenografted intraductally into mice and allowed to form tumors for 3 weeks, after which the mice received weekly injections of fulvestrant for 5 weeks. IHC showed that the level of $E R \alpha$ was lower in the tumors that received fulvestrant than in the vehicle-treated controls (Figure 10D), confirming that the drug had reached its target in vivo. To quantify the response, tumors were allowed to form in the mice for 3 weeks, treatment was given for 3 weeks, the injected mammary glands were excised and total tdTomato fluorescence was measured (Figure 10E). There was no significant difference between the treated and control groups (Figure 10F). The lack of response in vitro and in vivo mimics the resistance of human luminal B tumors to endocrine therapy in patients with breast cancer.

\section{Humanization of the mouse mammary gland}

The Weinberg laboratory has shown that "humanization" of the mouse mammary gland by human fibroblasts promotes engraftment of human mammary epithelial cells [27]. The epithelial cells form duct-like structures, but they do not ramify to fill the gland with a normal ductal tree, possibly because it is difficult to distribute human fibroblasts evenly throughout the fat pad. The logic behind this approach is that subtle differences in signaling proteins create a species barrier that prevents human myoepithelial cells from communicating properly with mouse fibroblasts. We reasoned that human luminal cells might be able to communicate effectively with mouse myoepithelial cells; therefore, we tried to use the mouse myoepithelial layer as a scaffold upon which to build a human luminal epithelium. We initially attempted to humanize the ducts of NSG mice by intraductal injection of reduction mammoplasty cells immortalized by TERT and BMI1 (" $2 \mathrm{G}$ " cells), but the cells were rapidly lost. To give the human cells a proliferative advantage over the resident murine luminal cells, we tested 4G-shp53 cells, which, as we described above, are nontumorigenic (Figure 6A). Three weeks after intraductal injection, there was much less fluorescence in the injected glands than after injection of their PIK3CA-transformed counterparts (Figure 11A). Histological examination showed that small clumps of human cells had penetrated the mouse luminal layer and had attached to the underlying murine myoepithelial layer (Figure 11B). By 6 weeks, large segments of the mammary ductal tree were fluorescent, indicating that viable human cells had engrafted and increased in number. The presence of alternating yellow and green regions showed that the grafts were derived from multiple different clones (Figure 12A). IHC for GFP confirmed that extensive regions of the ductal tree contained human cells (Figure 12B). Histologically, the human cells were slightly larger than the murine luminal cells, but there was no evidence of the premalignant changes of the sort usually observed in flat epithelial atypia or atypical ductal hyperplasia [29]. 

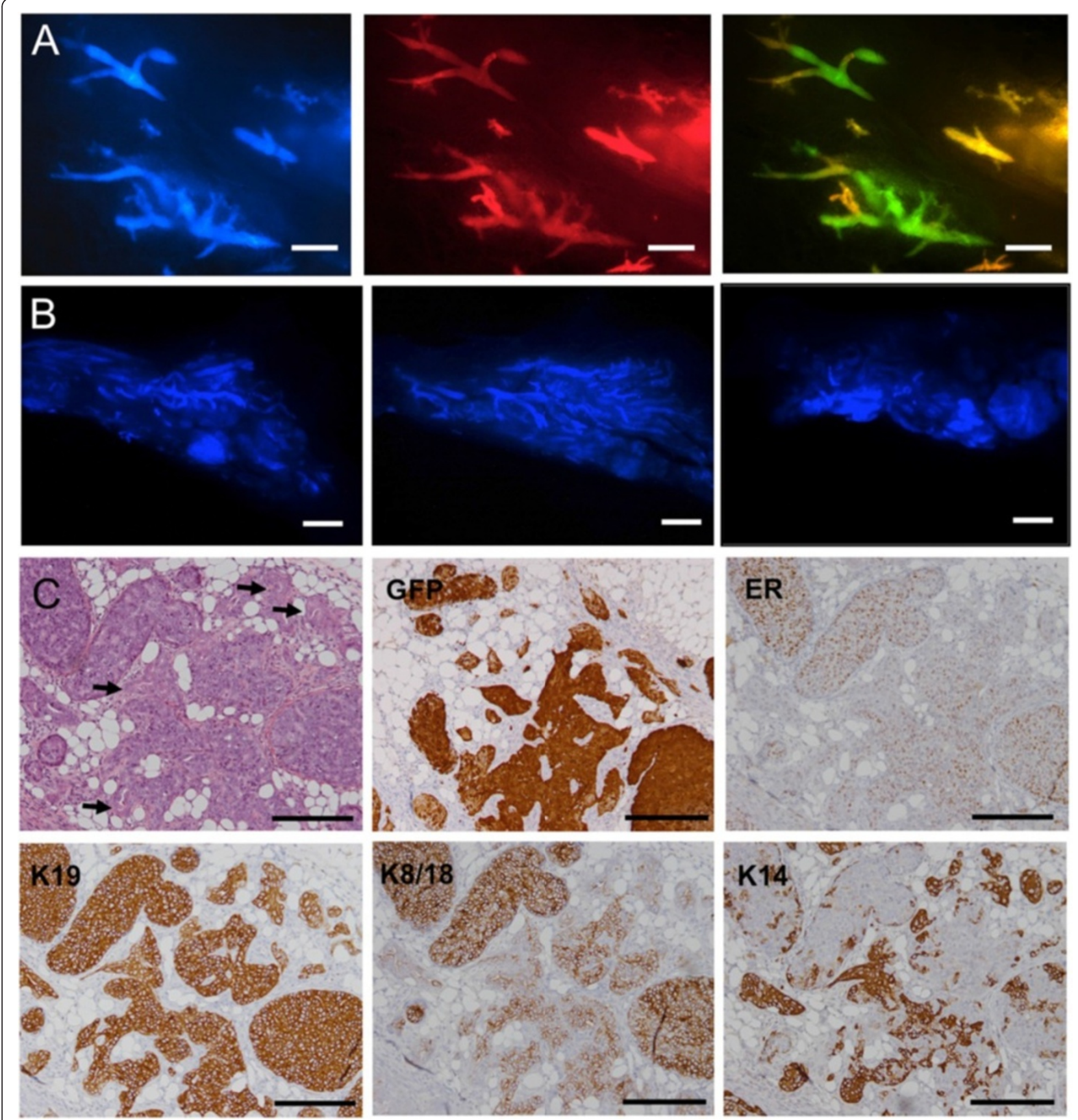

Figure 9 Invasive tumor formation 6 and 8 weeks after intraductal injection of 4G-shp53-PI3K tumor cells. (A) Mammary ducts dilated by human tumor cells at 6 weeks. (B) Diffuse blue masses 8 weeks after intraductal injection caused by tumor cells invading the stroma. (C) Mixed DCIS and invasive tumor at 8 weeks. Hematoxylin and eosin and immunohistochemical stains show increased keratin 14 (K14) staining as cells migrate from the ducts into the stroma. Early squamous changes are marked by arrows. There are small differences in the structures in the serial sections in (C) because the structures gradually change as the sectioning proceeds through the paraffin block. ER, Estrogen receptor; GFP, Green fluorescent protein; Scale bars $=1 \mathrm{~mm}$ (A), $2 \mathrm{~mm}$ (B) and $100 \mu \mathrm{m}$ (C), respectively.

Human cells replaced murine cells in the luminal layer, but the myoepithelial layer was murine, as shown by the absence of cells positive for both p63 and GFP in doublelabeled sections (Figure 13). The myoepithelial layer was intact, as judged by staining for SMA, but the number of myoepithelial cells was lower than in contiguous regions with murine luminal cells. All of the human cells expressed ER $\alpha$, and many expressed Ki67, but they did not express PGR, FOXA1 or GATA3 (Figure 12C and 12D), consistent with their in vitro profile. To test whether the 

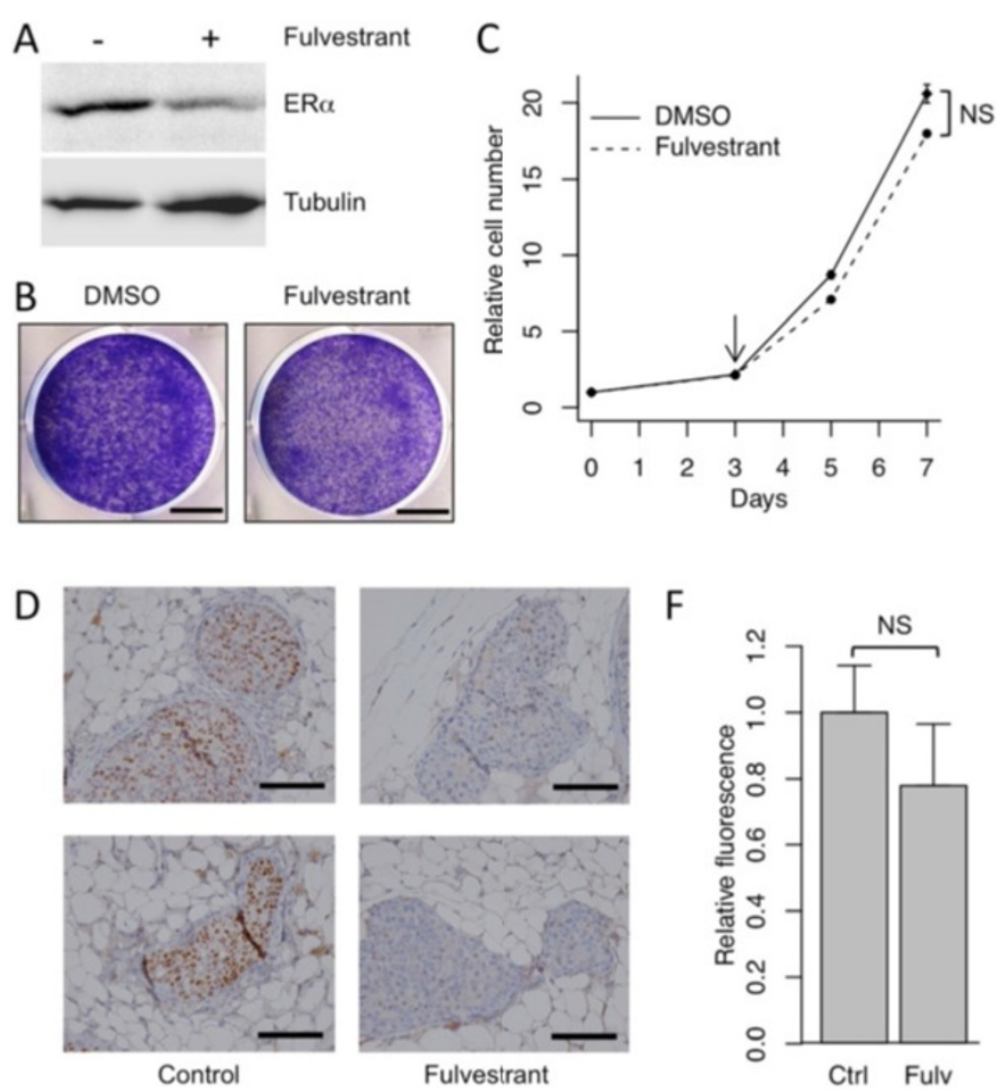

Control
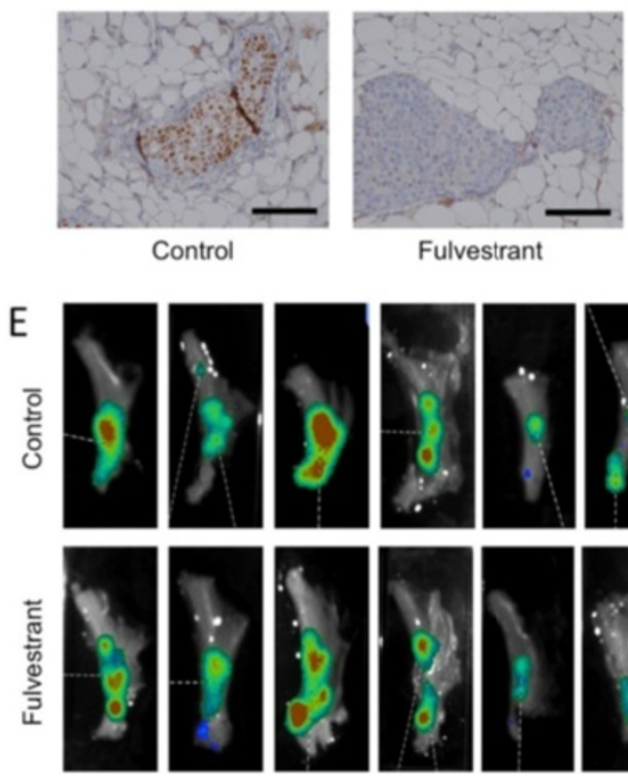

Fulvestrant
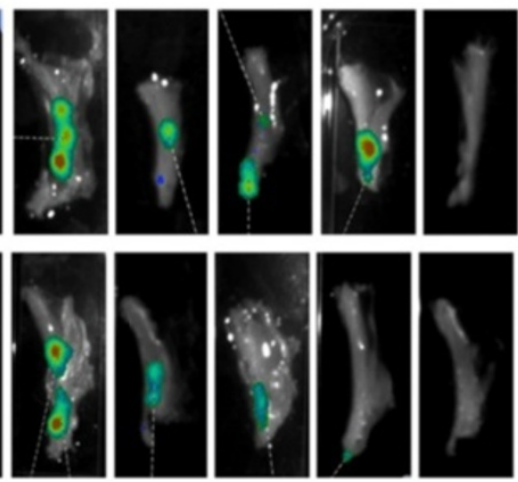

Figure 10 Tumor growth is not inhibited by fulvestrant. (A) Western blot showing that treatment of 4G-shp53-PI3K tumor cells with $1 \mu \mathrm{M}$ fulvestrant reduces the level of ERa. Fulvestrant has no effect on proliferation of the cells measured by crystal violet staining (B) or growth curves (C). Fulvestrant treatment was started at the arrow (day 3). $n=3$; DMSO, Dimethyl sulfoxide; NS, not significant. Scale bars $=1 \mathrm{~cm}$. (D) 4G-shp53-PI3K cells were injected into the ducts, allowed to form tumors for 3 weeks and then treated with fulvestrant or vehicle for 5 weeks. Representative immunohistochemical images show a marked reduction in ERa levels in treated tumors. Each image is derived from a separate animal $(n=6$ for control, $n=7$ for fulvestrant). The slides were all processed together. Scale bars $=50 \mu \mathrm{m}$. (E) and (F) 4G-shp53-PI3K cells were injected into the ducts, allowed to form tumors for 3 weeks and then treated with fulvestrant or vehicle for 3 weeks. PhotonIMAGER scans (E) of excised mammary glands after treatment with fulvestrant or vehicle (control) show how the response was quantified. The scanner counts fluorescence emitted by tdTomato. Graph in F shows quantitative data from the glands shown in $\mathrm{E}(n=8$ for control, $n=9$ for fulvestrant).

cells could differentiate to form secretory cells, they were injected into the mammary ducts of two mice and allowed to replace the luminal layer of the ducts. The mice were then mated and sacrificed on day 1 of lactation, 14 weeks after injection of the human cells. The human cells were restricted to the ducts and did not form alveoli, although some human cells in the ducts did undergo secretory differentiation (Figure 14: open arrowheads show murine alveoli; filled arrowheads show a nonsecretory humanized duct; and arrows show casein-expressing cells in a humanized duct). Taken together, the data suggest that the cells immortalized by the TERT, BMI1, CCND1, 

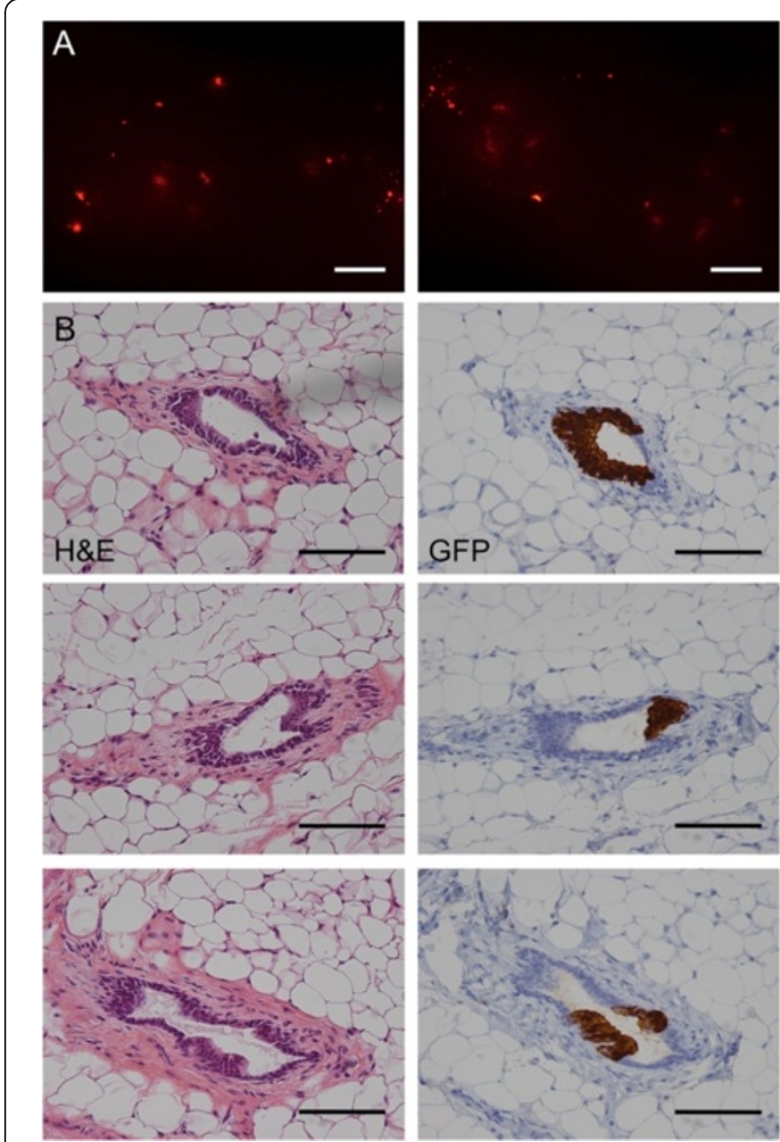

Figure 11 Foci of engrafted human cells 3 weeks after intraductal injection of $\mathbf{4 G - s h p 5 3}$ cells. (A) Stereomicrograph showing isolated foci of human cells. The images cover a single gland with a small overlap in the middle. Scale bar $=1 \mathrm{~mm}$. (B) Attachment of 4G-shp53 cells to the duct wall 3 weeks after intraductal injection. Left panels, hematoxylin and eosin (H\&E) staining. Right panels, matched sections showing green fluorescent protein (GFP) staining to identify the human cells. The clumps of human cells correspond to the scattered foci of fluorescent cells visualized by stereomicroscopy in (A). Scale bar $=100 \mu \mathrm{m} . n=2$ mice.

MYC and shp53 transgenes may be precursors of hormone-sensing or secretory cells trapped at the luminal progenitor stage.

\section{Discussion}

We have shown that genetically defined human mammary epithelial cells expressing multiple oncogenes can form a morphologically normal luminal layer in the mouse mammary gland and that expression of a single additional activated oncogene, PIK3CA-H1047R, is sufficient to convert them into invasive $E R \alpha+$ adenocarcinoma cells. Two factors were probably critical to the success of the approach: the use of oncogenes commonly mutated or amplified in ER $\alpha+$ breast cancer and the use of culture medium favoring ERBB3 over EGFR signaling to prevent squamous metaplasia in vitro.

Previous attempts to make breast cancer models by transformation of normal human mammary epithelial cells typically led to the formation of overtly squamous tumors that are unrepresentative of breast cancers seen in human patients. Several arguments implicate EGFR signaling in squamous metaplasia. First, EGFR is prominently expressed in the skin [22]. Second, the myoepithelial layer proliferates at the expense of the luminal layer in short-term organoid culture in media containing commonly used levels of EGF [3]. Third, deletion of Erbb3 in mice leads to loss of the luminal layer and expansion of the basal/myoepithelial layer [30]. Fourth, $E G F R$ is preferentially expressed by stem cells and basallike tumors, whereas ERBB3 is expressed by mature luminal cells and luminal tumors; luminal progenitors express both receptors, presumably because of their intermediate status (Figure 2 and [21,30]). To attenuate EGFR signaling, we replaced EGF in the culture medium with amphiregulin, which is 100-fold less active on EGFR [3], and added neuregulin, which activates ERBB3 and ERBB4 [31]. The WIT medium we used was developed specifically to promote the growth of luminal cells [2], but in the conditions we used, cell lines established in EGF-containing WIT medium underwent squamous metaplasia. Furthermore, our cell lines established in amphiregulin/neuregulin medium grow poorly if transferred back into EGF medium, suggesting that the amphiregulin/neuregulin combination not only prevents overgrowth of a confused myoepithelial population but also favors the growth of luminal cells. That said, we fully agree with Ince et al. [2] that WIT medium favors the growth of luminal cells. We suspect that the differences between our results and theirs reflect subtle differences in the formulation of the medium, the origin of the cells or the choice of transforming genes. Whatever the reason, our results indicate that replacement of EGF with amphiregulin and neuregulin is a simple modification that turns WIT into an even more robust luminalizing medium.

Transgenic mouse models frequently produce tumors with histological features rarely seen in human breast cancer patients. The striking feature of PI3K-induced mouse models is the extent to which they express ER $\alpha$, despite their unpromising histology [32]. This points to a role for PI3K in the regulation of ER $\alpha$ expression, but the cells in our model already formed ER $\alpha+$ xenografts before infection with the PIK3CA vector. The Kuperwasser group has described a model based on CCND1, PI3K, KRAS and TP53 that produces ER $\alpha+$ tumors [4,5]. $C C N D 1$ is a strong candidate for driving $E R \alpha+$ tumor formation in both our models because it is commonly amplified in ER $\alpha+$ tumors and activates ER $\alpha$ in the 

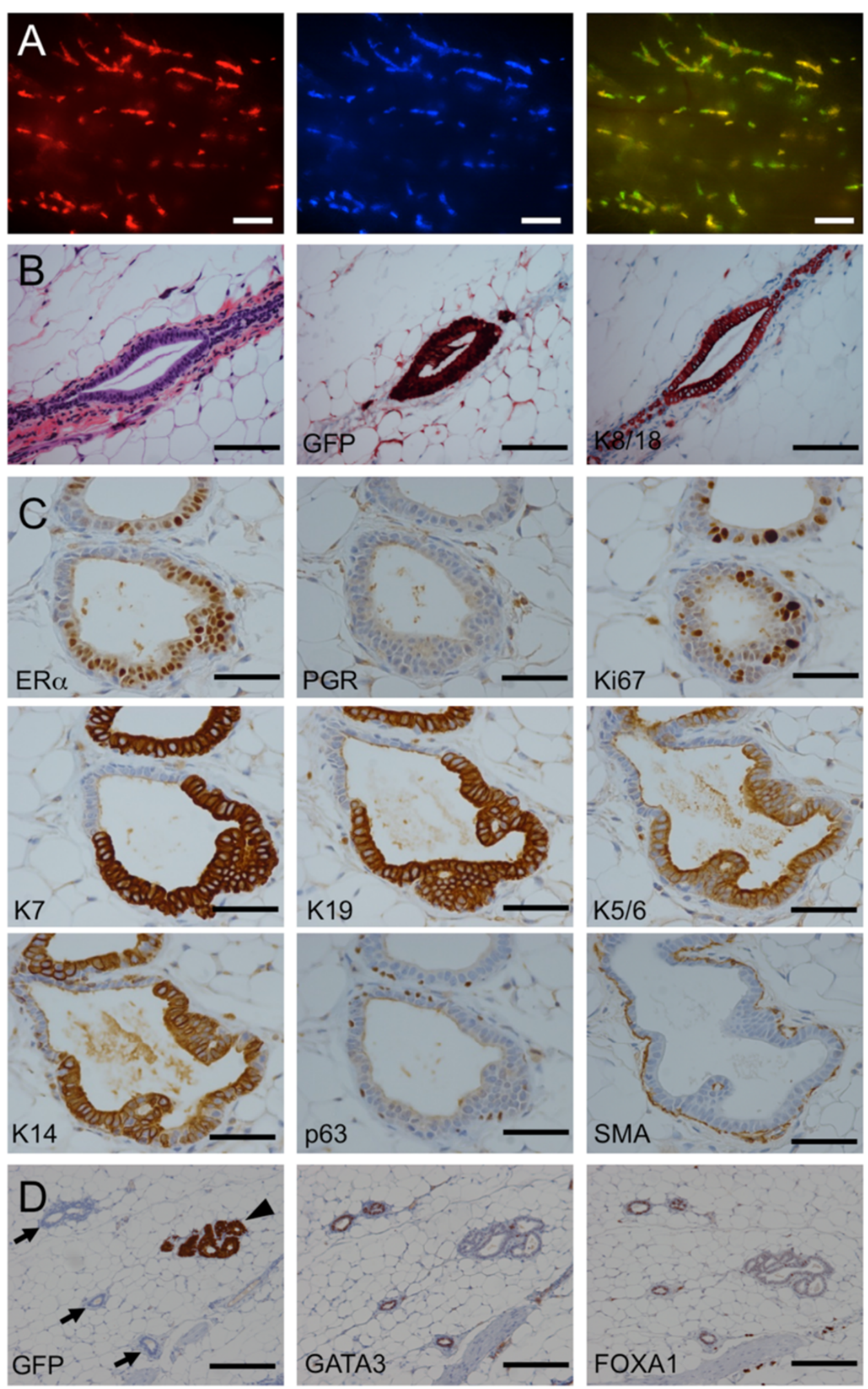

Figure 12 (See legend on next page.) 
(See figure on previous page.)

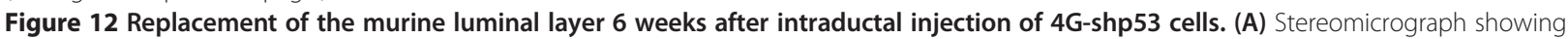
spread of human cells within the ducts. Alternating yellow and green areas in the right panel demonstrate independent engraftment of multiple clones. (B and C) Histopathology (hematoxylin and eosin stain) and immunohistochemistry show that the human cells have replaced the murine luminal layer with morphologically normal human cells. The human cells are larger, as seen at junctions between murine and human luminal cells. Green fluorescent protein (GFP), keratin 7 (K7) and keratin 19 (K19) staining specifically label the human cells. The cells are estrogen receptor a-positive (ERa+), progesterone receptor-negative (PGR-), Ki67+ luminal cells. Smooth muscle actin (SMA) staining shows that the myoepithelial layer is intact. (D) GATA binding protein 3 transcription factor (GATA3) and Forkhead box A1 transcription factor (FOXA1) are positive in murine ducts (marked by arrows), but negative in humanized ducts (marked by an arrowhead). Scale bars = 1 mm (A), $100 \mu \mathrm{m}$ (B), $50 \mu \mathrm{m}$ (C) and $200 \mu \mathrm{m}$ (D), respectively.

absence of hormone [33,34]. In addition to these arguments, the rationale for using CCND1, PI3K-H1047R, $M Y C, T E R T, B M I 1$ and sh-p53 was based on genomic data in luminal breast cancer and on past experience with mammary transformation protocols. According to the Cancer Genome Atlas Network, PIK3CA mutations are seen in $45 \%$ of luminal A tumors and $29 \%$ of luminal B tumors, and TP53 mutations are seen in 29\% of luminal B tumors [35]. $M Y C$ was included in the transformation cocktail because Elenbaas et al. reported that the endogenous $M Y C$ gene would amplify spontaneously if $M Y C$ was not supplied exogenously in their transformation protocol [36], and TERT was included to prevent telomere erosion [1]. BMI1 is preferentially expressed by luminal tumors [12,37] and cooperates well with $M Y C$ [38], but it was included mainly to prevent unwanted differentiation or genomic instability at early times after the cells were put into culture [12,39]. It is possible that

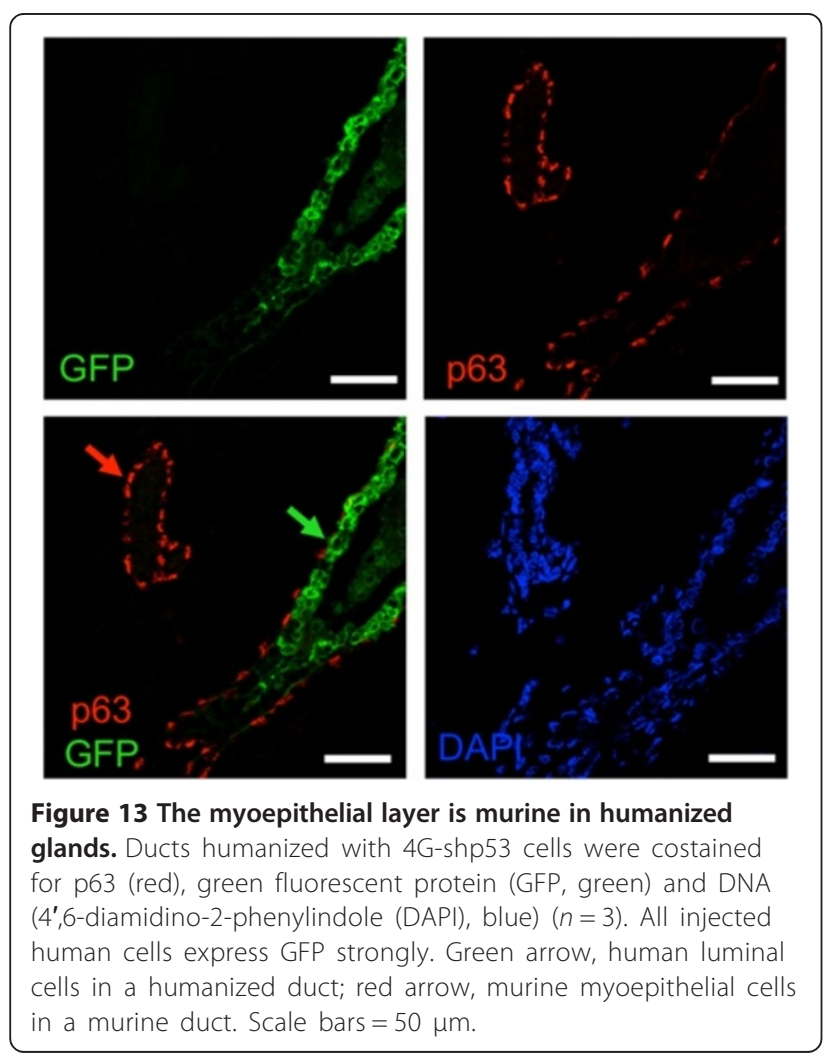

in the new medium it may not be necessary. BMI1 prevents activation of the p53 and $\mathrm{Rb}$ pathways [40], but the fact that silencing of p53 by RNA interference is required for full transformation in our model indicates that BMI1 is having at best a partial effect. We suspect this is because BMI1 is expressed at a low level by our lentiviral vector. After silencing of $\mathrm{p} 53$, the cells from the XS11 mammoplasty acquired a deletion on 3p21 starting within PBRM1, the gene encoding the BAF180 subunit of the polybromo- and BRG1-associated ATPdependent chromatin-remodeling complex [41]. Truncating mutations, as seen here, have previously been described in breast cancer, where they reduce p21 induction by transforming growth factor $\beta$ and p53 [25]. We have not performed CGH on multiple independently derived cell lines, so we cannot say whether this change is absolutely required for transformation with CCND1, PI3K-H1047R, MYC, TERT, BMI1 and sh-p53, but it seems unlikely. Indeed, the more striking feature is how flat the profiles are after transformation with defined oncogenes, something we also saw in our previous ER+ model [12].

Despite robust ER $\alpha$ expression, there was no response to fulvestrant. CCND1 and mutant PIK3CA can confer resistance to endocrine therapy in cell lines, but the relationship between PIK3CA mutation and the response to endocrine therapy is hotly debated [42]. Paradoxically, PIK3CA mutations are associated with a gene signature of low mammalian target of rapamycin complex 1 (mTORC1) signaling and better outcomes in $\mathrm{ER} \alpha+$ breast cancer [43]. It will be interesting to see whether the genetically defined $\mathrm{ER} \alpha+$ PIK3CA-mutant model we have developed can shed fresh light on this problem.

Genomic studies indicate that DCIS has a mutation profile similar to that seen in invasive cancer [44], and molecular clock studies indicate that breast tumors undergo little clonal expansion or genomic rearrangement until the last driver mutation is acquired [45]. Taken together, these results push the timeline for acquisition of oncogenic mutations far before the formation of DCIS. Our data following intraductal injection of 4Gshp53 cells show that cells with all but the last driver mutation can form a morphologically normal luminal 

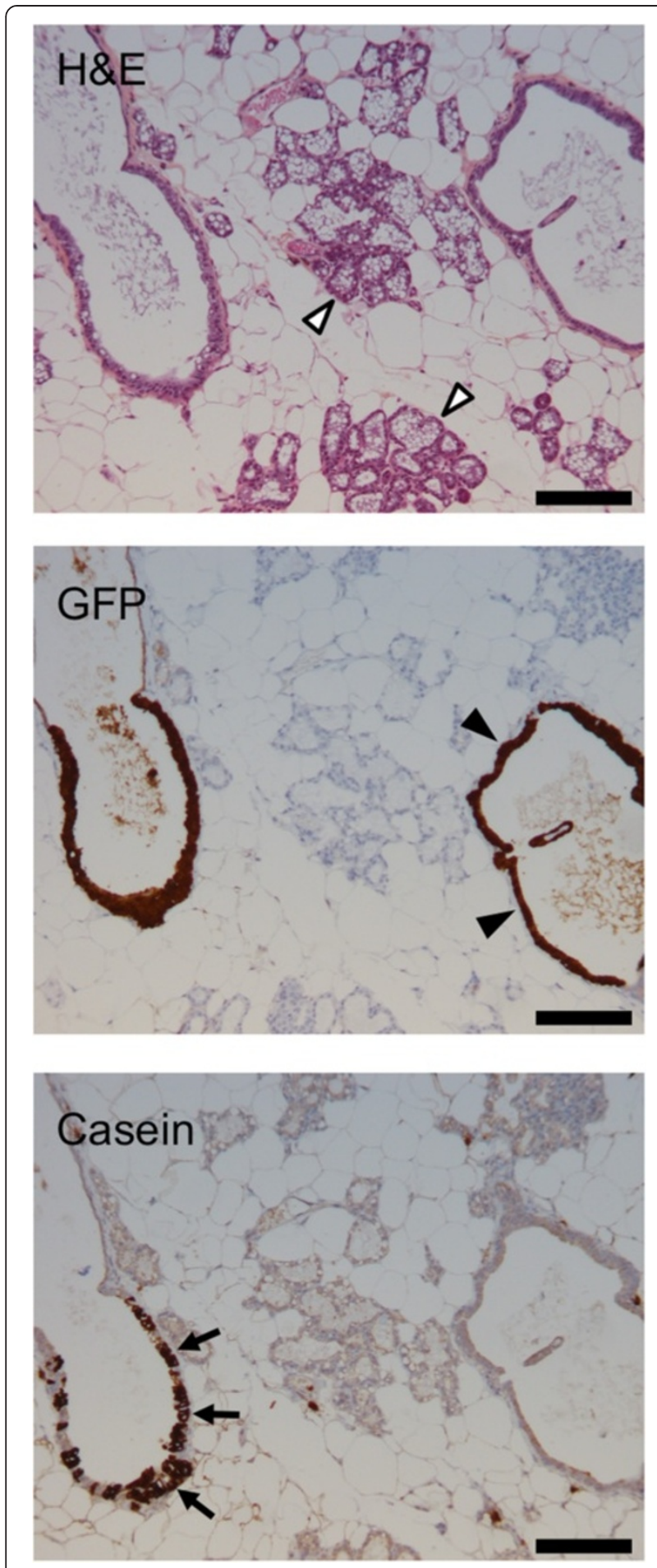

Figure 14 4G-shp53 cells can undergo secretory differentiation but do not form normal alveoli. Mice with human cells engrafted in the ducts were sacrificed on day 1 of lactation $(n=2)$. Hematoxylin and eosin (H\&E) stain and immunohistochemistry for green fluorescent protein (GFP) show that human cells are present in the ducts but do not spread into the lactating alveoli. Immunohistochemistry for casein shows that some of the human cells in the ducts have undergone secretory differentiation. The structures in the middle of the image are mouse alveoli (open arrowheads). They do not stain for casein, because the antibody is human-specific. The structure on the right is a humanized duct containing cells that do not express casein (closed arrowheads). The structure on the left is a humanized duct containing cells that do express casein (arrows). Scale bars $200 \mu \mathrm{m}$.

epithelium. The 4G-shp53 cells have a growth advantage over the murine luminal cells they replace, but, apart from being bigger than murine luminal cells, they are normal in appearance. They do not survive after subcutaneous injection, indicating that mammary ducts provide a more welcoming environment than skin. The microenvironment of the duct seems to promote glandular differentiation: the transformed cells were predominantly keratin 18-positive/keratin 14-negative while confined to the ducts, but keratin 14 expression increased when these cells migrated into the stroma. A possible interpretation of this is that the murine stroma is programmed to release EGF in amounts appropriate for murine progenitors but excessive for human progenitors [3]. Alternatively, the fact that occasional human cells bordering the necrotic core of the largest DCIS lesions expressed p63 suggests that squamous differentiation may be a cell-autonomous effect that normal myoepithelial cells prevent through release of a diffusible factor.

We see humanization of the luminal layer in the mouse ducts after intraductal injection as a form of tissue engineering in which the murine myoepithelial layer serves as a scaffold on which to build a human luminal layer. The failure of human cells to form a normal mammary ductal tree after xenografting into the mouse mammary fat pad is normally explained by the existence of a species barrier between human myoepithelial cells and mouse stromal cells. The Weinberg group has shown that this barrier can be partially overcome by infiltration of the mouse stroma with human fibroblasts [27]. Our results indicate that it may be better to retain the mouse myoepithelial layer and replace only the luminal layer with human cells. To do this, we used an intraductal xenografting approach developed by Behbod and colleagues, who showed that the approach is strikingly effective for growth of primary human DCIS cells in the mouse [10]. The DCIS histology in the mouse faithfully recapitulated the histology of the human sample from which it was derived and included regions where hyperplastic human cells formed single- and 
multilayered epithelia [11]. Taken together, our results suggest that intraductal grafting is a major advance over previous approaches to model human breast cancer biology in the mouse. We were not able to replace the murine luminal layer with unmodified human cells. Instead, we started with fully transformed cells and removed one oncogene, PIK3CA. Although the 4G-shp53 cells were able to form a morphologically normal luminal layer in the ducts, they were clearly not functionally normal, because they could not form normal alveolar structures in lactating mice. It will be interesting to test cells expressing even fewer oncogenes to determine the point at which human cells lose their competitive advantage over mouse cells, in order to see whether they can fully humanize the gland and produce functioning alveoli.

A weakness of mouse transgenic models in general is the strong tendency for tumor histology not to resemble that of human breast cancer. One reason may be a fundamental difference in the cell of origin of murine and human mammary tumors. Recent work carried out in the Blanpain laboratory has identified a long-lived luminal stem cell [6] whose human homolog is a strong candidate for the cell of origin of luminal, molecular apocrine and basal-like human breast cancers. The ER $\alpha+$, ELF5 + cell in our cultures could be the preneoplastic counterpart of this cell. Recent work done in the Ormandy laboratory indicates that ER $\alpha$ and ELF5 crossinhibit one another in luminal progenitors, with definitive hormone-sensing or secretory lineage differentiation ensuing when one factor triumphs over the other [24]. This is perfectly consistent with the failure of our transformed cells to respond to inhibition of ER $\alpha$ with fulvestrant. Drawing parallels between normal lineages and tumor cells is fraught with difficulty because tumor cells inevitably fail many of the tests cell biologists use to characterize normal cells, such as differentiation of progenitors into mature, terminally differentiated cells. Nevertheless, taken together, our data suggest that injection of genetically engineered human cells into the mouse mammary ducts may provide a strategy to study the differentiation of normal and malignant human mammary epithelial cells in a more physiological context than has hitherto been possible.

\section{Conclusion}

We have shown that altering the balance of EGFR family signaling in favor of ERBB3/ERBB4 prevents squamous metaplasia of mammary epithelial cells in vitro, that human cells with multiple defined oncogenic changes can replace the luminal cell layer in the mouse mammary gland with a morphologically normal luminal layer of human cells, and that addition of a single activated oncogene, mutant PIK3CA, is sufficient to convert these cells into invasive $\mathrm{ER} \alpha+$ adenocarcinoma cells.

\section{Additional files}

\begin{abstract}
Additional file 1: Figure S1. Western blots showing expression of the transgenes in 4G and parental cells (A) and lack of FOXA1 and GATA3 expression in $4 \mathrm{G}$ cells (B). MCF7 cells were used as a positive control for the FOXA1 and GATA3 blots. p4 to p6, different passages of the 4G cells in sVWIT medium.

Additional file 2: Figure S2. Transformation in sVWIT with different mammoplasties (XSO3 and XS05). Western blots showing expression of the TERT, BMI1, MYC and CCND1 transgenes $(\mathbf{A})$ and phosphorylation of AKT on T308 induced by PI3K (B). Flow cytometry shows the formation of single populations of EPCAM+ cells after transformation in XS05 (C) and XS03 (D). The quadrants were defined by the isotype controls. 4G-shp53 cells are unable to survive after subcutaneous xenografting. Only the cells superinfected with the PIK3CA vector survive and form tumors in XS05 (E) and XSO3 (F) $(n=5)$. (G) DCIS after intraductal injection of XS05 4G-shp53-PI3K cells (H\&E staining and IHC for ERa Ki67, GFP, p63, SMA and keratins). Scale bars, $100 \mu \mathrm{m}$.
\end{abstract}

\section{Abbreviations}

4G cells: Breast primary epithelial cells transduced with TERT, BMI1, MYC and CCND1 lentiviral vectors; 4G-shp53 cells: 4G cells transduced with sh-TP53 lentiviral vector; 4G-shp53-PI3K cells: 4G-shp53 cells transduced with PIK3CAH1047R lentiviral vector; Addgene: Plasmid repository (http://www.addgene.org); AKT: v-Akt murine thymoma viral oncogene; AREG: Amphiregulin; BMI1: B lymphoma Moloney murine leukemia virus insertion region 1 oncogene; BPEC: Breast primary epithelial cell; CCND1: Cyclin D1; CD10: Membrane metalloendopeptidase (MME, CALLA); CD49f: Integrin, alpha 6 (ITGA6); CFP: Cyan fluorescent protein; $\mathrm{CGH}$ : Comparative genomic hybridization; DCIS: Ductal carcinoma in situ; EGF: Epidermal growth factor; EGFR: Epidermal growth factor receptor; ELF5: E74-like factor 5 (ETS-domain transcription factor); EPCAM: Epithelial cell adhesion molecule; ERBB2: Epidermal growth factor receptor homolog 2 (v-erb-b2 avian erythroblastic leukemia viral oncogene homolog 2); ERBB3: Epidermal growth factor receptor homolog 3 (v-erb-b2 avian erythroblastic leukemia viral oncogene homolog 3); ERBB4: Epidermal growth factor receptor homolog 4 (v-erb-b2 avian erythroblastic leukemia viral oncogene homolog 4); ESR1/ERa: Estrogen receptor a; FOXA1: Forkhead box A1 transcription factor; GATA3: GATA binding protein 3 transcription factor; GFP: Green fluorescent protein; IHC: Immunohistochemistry; Ki67: Antigen encoded by the MKI67 gene, recognized by the Ki67 antibody; NRG1: Neuregulin 1; NSG: Nonobese diabetic, severe combined immunodeficiency, interleukin 2 receptor gamma chain-null mouse; PDK1: Pyruvate dehydrogenase kinase isoenzyme 1; PGR: Progesterone receptor; PIK3CA: Phosphatidylinositol-4,5bisphosphate 3-kinase catalytic subunit a; PlasmID: Plasmid Repository (http://plasmid.med.harvard.edu/PLASMID/Home.xhtml); pWIT: WIT medium for primary cells, contains $10 \mathrm{ng} / \mathrm{ml}$ epidermal growth factor; RMA: Robust multiarray average gene expression measure; SMA: Smooth muscle actin; sVWIT: WIT medium containing $5 \mathrm{ng} / \mathrm{ml} \mathrm{NRG1}$ and $10 \mathrm{ng} / \mathrm{ml}$ AREG; tdTomato: Red fluorescent protein; TERT: telomerase catalytic subunit; TP53: Tumor protein p53; WIT: Mammary culture medium developed by Tan Ince [2].

\section{Competing interests}

The authors declare that they have no competing interests.

\section{Authors' contributions}

SV and ER performed molecular biology, cell biology and animal experiments. EM and XS performed cell biology experiments. BR performed animal experiments. W performed IHC. GMG performed pathological analysis. RI conceived the study. HB, GMG, DB and RI participated in its design and coordination. SV, ER and RI drafted the manuscript. All authors read and approved the final manuscript.

\section{Acknowledgements}

We thank the French National Cancer Institute (grants plbio 2010-181, plbio 2010-216 and INCa-DGOS-Inserm 6046), the French National Cancer League (grant Equipe Labellisee Ligue Contre le Cancer 2011) and Fondation Widmer 
for funding to H. Bonnefoi and R Iggo. We thank the Tayside Tissue bank for providing reduction mammoplasty tissue; the Bergonie Institute microarray platform for performing CGH; Birgit and David Lane for providing antibodies; and Addgene, PlasmID, their contributing scientists and Francois Moreau-Gaudry for providing plasmids.

\section{Author details}

'INSERM U916, Bergonié Cancer Institute, University of Bordeaux, 229 cours de l'Argonne, Bordeaux 33076, France. ${ }^{2}$ School of Medicine, University of St Andrews, Medical and Biological Sciences Building, North Haugh, St Andrews KY16 9TF, UK. ${ }^{3}$ Animalerie A2, University of Bordeaux, 146 rue Léo Saignat, 33076 Bordeaux, France. ${ }^{4}$ Pathology Department, Bergonié Cancer Institute, 229 cours de l'Argonne, 33076 Bordeaux, France. ${ }^{5}$ INSERM U1052, Centre Leon Berard, University of Lyon, 28 rue Laennec, 69008 Lyon, France.

Received: 8 July 2014 Accepted: 11 December 2014

Published online: 20 December 2014

\section{References}

1. Hahn WC, Counter CM, Lundberg AS, Beijersbergen RL, Brooks MW, Weinberg RA: Creation of human tumour cells with defined genetic elements. Nature 1999, 400:464-468.

2. Ince TA, Richardson AL, Bell GW, Saitoh M, Godar S, Karnoub AE, Iglehart JD, Weinberg RA: Transformation of different human breast epithelial cell types leads to distinct tumor phenotypes. Cancer Cell 2007, 12:160-170.

3. Pasic L, Eisinger-Mathason TS, Velayudhan BT, Moskaluk CA, Brenin DR, Macara IG, Lannigan DA: Sustained activation of the HER1-ERK1/2-RSK signaling pathway controls myoepithelial cell fate in human mammary tissue. Genes Dev 2011, 25:1641-1653.

4. Keller PJ, Arendt LM, Skibinski A, Logvinenko T, Klebba I, Dong S, Smith AE, Prat A, Perou CM, Gilmore H, Schnitt S, Naber SP, Garlick JA, Kuperwasser C Defining the cellular precursors to human breast cancer. Proc Natl Acad Sci USA 2012, 109:2772-2777.

5. Proia TA, Keller PJ, Gupta PB, Klebba I, Jones AD, Sedic M, Gilmore H, Tung N, Naber SP, Schnitt S, Lander ES, Kuperwasser C: Genetic predisposition directs breast cancer phenotype by dictating progenitor cell fate. Cell Stem Cell 2011, 8:149-163.

6. Van Keymeulen A, Rocha AS, Ousset M, Beck B, Bouvencourt G, Rock J, Sharma N, Dekoninck S, Blanpain C: Distinct stem cells contribute to mammary gland development and maintenance. Nature 2011, 479:189-193.

7. Wellings SR, Jensen HM: On the origin and progression of ductal carcinoma in the human breast. J Nat/ Cancer Inst 1973, 50:1111-1118

8. DeOme KB, Faulkin $\sqcup \mathrm{Jr}$, Bern HA, Blair PB: Development of mammary tumors from hyperplastic alveolar nodules transplanted into gland-free mammary fat pads of female C3H mice. Cancer Res 1959, 19:515-520.

9. Eirew P, Stingl J, Raouf A, Turashvili G, Aparicio S, Emerman JT, Eaves CJ: A method for quantifying normal human mammary epithelial stem cells with in vivo regenerative ability. Nat Med 2008, 14:1384-1389.

10. Behbod F, Kittrell FS, LaMarca H, Edwards D, Kerbawy S, Heestand JC, Young E, Mukhopadhyay P, Yeh HW, Allred DC, Hu M, Polyak K, Rosen JM, Medina D: An intraductal human-in-mouse transplantation model mimics the subtypes of ductal carcinoma in situ. Breast Cancer Res 2009, 11:R66.

11. Valdez KE, Fan F, Smith W, Allred DC, Medina D, Behbod F: Human primary ductal carcinoma in situ (DCIS) subtype-specific pathology is preserved in a mouse intraductal (MIND) xenograft model. J Pathol 2011, 225:565-573.

12. Duss S, André S, Nicoulaz AL, Fiche M, Bonnefoi H, Brisken C, Iggo RD: An oestrogen-dependent model of breast cancer created by transformation of normal human mammary epithelial cells. Breast Cancer Res 2007, 9:R38.

13. Harlow E, Lane D: Antibodies: A Laboratory Manual. Cold Spring Harbor, NY: Cold Spring Harbor Laboratory Press; 1988.

14. Lim E, Vaillant F, Wu D, Forrest NC, Pal B, Hart AH, Asselin-Labat ML, Gyorki DE, Ward T, Partanen A, Feleppa F, Huschtscha LI, Thorne HJ, kConFab, Fox SB, Yan M, French JD, Brown MA, Smyth GK, Visvader JE, Lindeman GJ: Aberrant luminal progenitors as the candidate target population for basal tumor development in BRCA1 mutation carriers. Nat Med 2009, 15:907-913.

15. Farmer $\mathrm{P}$, Bonnefoi $\mathrm{H}$, Anderle $\mathrm{P}$, Cameron $\mathrm{D}$, Wirapati $\mathrm{P}$, Becette $\mathrm{V}$, André $\mathrm{S}$, Piccart M, Campone M, Brain E, MacGrogan G, Petit T, Jassem J, Bibeau F, Blot E, Bogaerts J, Aguet M, Bergh J, Iggo R, Delorenzi M: A stroma-related gene signature predicts resistance to neoadjuvant chemotherapy in breast cancer. Nat Med 2009, 15:68-74

16. Bonnefoi $H$, Piccart $M$, Bogaerts J, Mauriac L, Fumoleau P, Brain E, Petit T, Rouanet $\mathrm{P}$, Jassem J, Blot $\mathrm{E}$, Zaman $\mathrm{K}$, Cufer T, Lortholary A, Lidbrink $\mathrm{E}$, André S, Litière S, Lago LD, Becette V, Cameron DA, Bergh J, Iggo R, EORTC 10994/BIG 1-00 Study Investigators: TP53 status for prediction of sensitivity to taxane versus non-taxane neoadjuvant chemotherapy in breast cancer (EORTC 10994/BIG 1-00): a randomised phase 3 trial. Lancet Oncol 2011, 12:527-539. A published erratum appears in Lancet Oncol 2013, 14:e47.

17. R Core Team: R: A Language and Environment for Statistical Computing. R Foundation for Statistical Computing, Vienna, Austria. [http://www.R-project.org/]

18. Farmer $P$, Bonnefoi $H$, Becette $V$, Tubiana-Hulin $M$, Fumoleau $P$, Larsimont $D$, MacGrogan G, Bergh J, Cameron D, Goldstein D, Duss S, Nicoulaz AL, Brisken C, Fiche M, Delorenzi M, Iggo R: Identification of molecular apocrine breast tumours by microarray analysis. Oncogene 2005, 24:4660-4671.

19. Stingl J, Emerman JT, Eaves CJ: Enzymatic dissociation and culture of normal human mammary tissue to detect progenitor activity. Methods Mol Biol 2005, 290:249-263

20. Naldini L, Blömer U, Gallay P, Ory D, Mulligan R, Gage FH, Verma IM, Trono $D$ : In vivo gene delivery and stable transduction of nondividing cells by a lentiviral vector. Science 1996, 272:263-267.

21. Lim E, Wu D, Pal B, Bouras T, Asselin-Labat ML, Vaillant F, Yagita $H$, Lindeman GJ, Smyth GK, Visvader JE: Transcriptome analyses of mouse and human mammary cell subpopulations reveal multiple conserved genes and pathways. Breast Cancer Res 2010, 12:R21.

22. Gusterson B, Cowley G, Smith JA, Ozanne B: Cellular localisation of human epidermal growth factor receptor. Cell Biol Int Rep 1984, 8:649-658.

23. van Agthoven T, Timmermans M, Foekens JA, Dorssers LC, HenzenLogmans SC: Differential expression of estrogen, progesterone, and epidermal growth factor receptors in normal, benign, and malignant human breast tissues using dual staining immunohistochemistry. Am J Pathol 1994, 144:1238-1246.

24. Kalyuga M, Gallego-Ortega D, Lee HJ, Roden DL, Cowley MJ, Caldon CE, Stone A, Allerdice SL, Valdes-Mora F, Launchbury R, Statham AL, Armstrong N, Alles MC, Young A, Egger A, Au W, Piggin CL, Evans CJ, Ledger A, Brummer T, Oakes SR, Kaplan W, Gee JM, Nicholson RI, Sutherland RL, Swarbrick A, Naylor MJ, Clark SJ, Carroll JS, Ormandy CJ: ELF5 suppresses estrogen sensitivity and underpins the acquisition of antiestrogen resistance in luminal breast cancer. PLOS Biol 2012, 10:e1001461.

25. Xia W, Nagase S, Montia AG, Kalachikov SM, Keniry M, Su T, Memeo L, Hibshoosh H, Parsons R: BAF180 is a critical regulator of p21 induction and a tumor suppressor mutated in breast cancer. Cancer Res 2008, 68:1667-1674

26. Moll R, Franke WW, Schiller DL, Geiger B, Krepler R: The catalog of human cytokeratins: patterns of expression in normal epithelia, tumors and cultured cells. Cell 1982, 31:11-24.

27. Kuperwasser C, Chavarria T, Wu M, Magrane G, Gray JW, Carey L, Richardson A, Weinberg RA: Reconstruction of functionally normal and malignant human breast tissues in mice. Proc Natl Acad Sci U S A 2004, 101:4966-4971.

28. Abd El-Rehim DM, Pinder SE, Paish CE, Bell J, Blamey RW, Robertson JF, Nicholson RI, Ellis 1O: Expression of luminal and basal cytokeratins in human breast carcinoma. J Pathol 2004, 203:661-671.

29. Lakhani SR, Ellis IO, Schnitt SJ, Tan PH, van de Vijver MJ (Eds): IARCMHO Classification of Tumours, Volume 4: WHO Classification of Tumours of the Breast. 4th edition. Geneva: World Health Organization (WHO); 2012.

30. Balko JM, Miller TW, Morrison MM, Hutchinson K, Young C, Rinehart C, Sanchez V, Jee D, Polyak K, Prat A, Perou CM, Arteaga CL, Cook RS: The receptor tyrosine kinase ErbB3 maintains the balance between luminal and basal breast epithelium. Proc Natl Acad Sci U S A 2012, 109:221-226.

31. Hynes NE, Lane HA: ERBB receptors and cancer: the complexity of targeted inhibitors. Nat Rev Cancer 2005, 5:341-354. A published erratum appears in Nat Rev Cancer 2005, 5:580.

32. Koren S, Bentires-Alj M: Mouse models of PIK3CA mutations: one mutation initiates heterogeneous mammary tumors. FEBS J 2013, 280:2758-2765.

33. Zwijsen RM, Buckle RS, Hijmans EM, Loomans CJ, Bernards R: Ligandindependent recruitment of steroid receptor coactivators to estrogen receptor by cyclin D1. Genes Dev 1998, 12:3488-3498.

34. Zwijsen RM, Wientjens E, Klompmaker R, van der Sman J, Bernards R, Michalides RJ: CDK-independent activation of estrogen receptor by cyclin D1. Cell 1997, 88:405-415. 
35. Cancer Genome Atlas Network: Comprehensive molecular portraits of human breast tumours. Nature 2012, 490:61-70.

36. Elenbaas B, Spirio L, Koerner F, Fleming MD, Zimonjic DB, Donaher JL, Popescu NC, Hahn WC, Weinberg RA: Human breast cancer cells generated by oncogenic transformation of primary mammary epithelial cells. Genes Dev 2001, 15:50-65.

37. Pietersen AM, Horlings HM, Hauptmann M, Langerod A, Ajouaou A, Cornelissen-Steijger P, Wessels LF, Jonkers J, van de Vijver MJ, van Lohuizen M: EZH2 and BMI1 inversely correlate with prognosis and TP53 mutation in breast cancer. Breast Cancer Res 2008, 10:R109.

38. van Lohuizen $M$, Verbeek $S$, Scheijen B, Wientjens $E$, van der Gulden $H$, Berns $A$ : Identification of cooperating oncogenes in $E \mu-m y c$ transgenic mice by provirus tagging. Cell 1991, 65:737-752.

39. Cudré-Mauroux C, Occhiodoro T, König S, Salmon P, Bernheim L, Trono D: Lentivector-mediated transfer of Bmi-1 and telomerase in muscle satellite cells yields a Duchenne myoblast cell line with long-term genotypic and phenotypic stability. Hum Gene Ther 2003, 14:1525-1533.

40. Sherr CJ: Tumor surveillance via the ARF-p53 pathway. Genes Dev 1998, 12:2984-2991.

41. Wilson BG, Roberts CW: SWI/SNF nucleosome remodellers and cancer. Nat Rev Cancer 2011, 11:481-492.

42. Zardavas D, Phillips W, Loi S: PIK3CA mutations in breast cancer: reconciling findings from preclinical and clinical data. Breast Cancer Res 2014, 16:201.

43. Loi S, Haibe-Kains B, Majjaj S, Lallemand F, Durbeca V, Larsimont D, Gonzalez-Angulo AM, Pusztai L, Symmans WF, Bardelli A, Ellis P, Tutt AN, Gillett CE, Hennessy BT, Mills GB, Phillips WA, Piccart MJ, Speed TP, McArthur GA, Sotiriou C: PIK3CA mutations associated with gene signature of low mTORC1 signaling and better outcomes in estrogen receptor-positive breast cancer. Proc Natl Acad Sci U S A 2010, 107:10208-10213.

44. Lopez-Garcia MA, Geyer FC, Lacroix-Triki M, Marchió C, Reis-Filho JS: Breast cancer precursors revisited: molecular features and progression pathways. Histopathology 2010, 57:171-192.

45. Nik-Zainal S, Van Loo P, Wedge DC, Alexandrov LB, Greenman CD, Lau KW, Raine K, Jones D, Marshall J, Ramakrishna M, Shlien A, Cooke SL, Hinton J, Menzies A, Stebbings LA, Leroy C, Jia M, Rance R, Mudie LJ, Gamble SJ, Stephens PJ, McLaren S, Tarpey PS, Papaemmanuil E, Davies HR, Varela I, McBride DJ, Bignell GR, Leung K, Butler AP, the Breast Cancer Working Group of the International Cancer Genome Consortium, et al: The life history of 21 breast cancers. Cell 2012, 149:994-1007.

\section{Submit your next manuscript to BioMed Central and take full advantage of:}

- Convenient online submission

- Thorough peer review

- No space constraints or color figure charges

- Immediate publication on acceptance

- Inclusion in PubMed, CAS, Scopus and Google Scholar

- Research which is freely available for redistribution 